\title{
Reverse logistics research of municipal hazardous waste: a literature review
}

\author{
Chunlin Xin ${ }^{1}$. Jie Wang ${ }^{1}$ - Ziping Wang ${ }^{2} \cdot$ Chia-Huei Wu ${ }^{3} \cdot$ Muhammad Nawaz ${ }^{1}$. \\ Sang-Bing Tsai ${ }^{4}$ D
}

Received: 9 October 2019 / Accepted: 15 May 2021 / Published online: 3 June 2021

(c) The Author(s), under exclusive licence to Springer Nature B.V. 2021

\begin{abstract}
The reverse logistics of municipal hazardous waste (RLMHW) have received close attention from researchers and practitioners alike, given the essential impact of safe transportation and effective management of hazardous waste on public health and environmental sustainability. There are a great number of studies in the extant literature on RLMHW, with many and diverse research topics; however, a concise and complete overview of the research works already conducted in this particular area is conspicuous by its absence. This paper strives to fill the gap through the conduct of rigorous systematic literature review of RLMHW in the past three decades, and then establish a framework of studies on RLMHW. The main contributions of this study are as follows: (1) to identify the trend of journals publishing research papers on RLMHW; (2) to extract the main topics in studies on RLMHW; (3) to locate the most popular research areas of RLMHW; (4) to summarize the methods adopted in studies on RLMHW; (5) to identify research deficiencies in certain categories of RLMHW; and (6) to establish the future research directions of RLMHW. The main implications of the study are to offer a better understanding of RLMHW by systematic crystallization of archival data in a systematic chronological order across central issues. This study contributes to scholarly debate in this field by serving as a snapshot paper to document the development of the field and gives input to policymakers in process design and policy making in the domain of RLMHW.
\end{abstract}

Keywords Municipal hazardous waste $\cdot$ Reverse logistics $\cdot$ Literature review Sustainability

Chia-Huei Wu

chiahuei530@gmail.com

Sang-Bing Tsai

sangbing@hotmail.com

Extended author information available on the last page of the article 


\section{Introduction}

"Hazardous waste" has different definitions in different countries. It was roughly identified as non-household waste including hazardous chemical waste (Ceccarini et al., 2017). "According to the US Environmental Protection Agency (2009), waste is hazardous if it poses a substantial threat to human health or the environment" (Greer, 1984). Greer also categorized hazardous waste as nuclear waste, industrial waste, medical waste, constructional waste, electronic waste and general waste including household waste. Thus, the hazardous waste discussed in this study refers to waste generated from municipalities, including industrial dangerous waste, medical waste, electronic waste, and any other waste that is harmful to public health and the environment.

Reverse logistics of hazardous waste (RLHW) is the material flow formed by collecting, classifying, processing, packaging, transporting, and storing hazardous objects from economic activities and distributing them to specific treatment facilities. Therefore, the activities of reverse logistics of hazardous waste involve many issues such as network location, collection, vehicle routing and network design. An assortment of waste and sub-product is caused by numerous industrial sectors, such as food, healthcare, and mining (Guimarães et al. 2018). Approximately $40 \%$ of the cause of the waste by these sources are categorized as hazardous, which must be facilitated in a way to stop from appearing negative effect on the environment and people's health (Guimarães et al. 2018). According to Alumur and Kara (2007) also noted that the reverse logistics of hazardous waste include several segments, e.g., network location, collection, transportation, and processing. Many issues still exist in the management of each of the above-stated segments above, especially in the context of developing countries, where inappropriate handling of hazardous waste leads to severe damage in terms of public health as well as the environment. Therefore, it is necessary to further study the reverse logistics of hazardous waste.

And as we all know, review papers play a significant role in analysing and assessing the past, current, and future trends in a field of subject. In the literature, no paper has reviewed and summarized the studies on RLHW in entirety amidst individual fragmented efforts by some leading researchers. This study endeavours to synthesize the existing body of literature on RLMHW are conspicuous by its absence. This study strives to fill the gap in scholarly debate through conducts of a rigorous systematic review of the extant literature of RLHW for the last three decades (from January 1990 to September 2002) to examine the practice of RLHW and to determine the potential fields for future studies. In addition, this study aims to assess current major research topics in RLHW as well as the emergent key research issues that need to be solved. As a consequence, this is a multi-dimensional creative study that attempts to determine key journal publication outlets on RLHW, main topics, focus and research methods of studies undertaken in domains of RLHW as well as serves as a vehicle to determine future research directions.

To fulfil the above-stated research objectives, this study considers papers published in well-acknowledged journals since January 1990, and these journals come from various research fields such as the Journal of Cleaner Production, Waste Management, and Waste Management \& Research.

This study endeavours to contribute to the existing body of literature through a longitudinal stance in the form of a systematic literature review. It strives to indicate the importance of RLHW in domains of hazardous waste by comparing and contrasting key research areas of various journals across the globe and by identification of future research directions. The main contributions of this study are as follows: (1) to identify the trend of 
journals publishing research papers on RLMHW; (2) to extract the main topics in studies on RLMHW; (3) to locate the most popular research areas of RLMHW; (4) to summarize the methods adopted in studies on RLMHW; and (5) to establish the future research directions of RLMHW.

The remainder of the article is organized as follows. In Sect. 2, the research method and process are described. Then, a detailed analysis of the literature content is conducted in Sect. 3. The analysis results and the deficiency of the current research are presented in Sect. 4. Finally, the conclusions are summarized, and some future directions are suggested in Sect. 5. The whole research framework of this study is given in Fig. 1.

\section{Research methodology}

This study uses the Navigation Guide methodology (IARC, 2006) recommended by the United States Environmental Protection Agency (US EPA) and World Health Organization (WHO) in the first place to lay down the selection criteria and then follow the four steps suggested by Woodruff and Sutton (2014), Van Engeland et al. (2020) to analyse the extant literature in domains of reverse logistics of hazardous waste. These four steps consist of (1) specifying the study questions, (2) selecting the evidence, (3) rating the quality and strength of the evidence, and (4) grading the strength of the recommendations (Woodruff $\&$ Sutton, 2014). This process is consistent with the model for qualitative content analysis developed by Mayring (2003). To be specific, Mayring's model comprises the following four steps: material collection, descriptive analysis, category selection and material evaluation (Mayring, 2007).

To systematically review the literature, this study will implement both qualitative techniques and quantitative tools based on the process presented by Mayring (2007) and Woodruff and Sutton (2014). A holistic and structural view of the research in RLHW is expected. Following Mayring (2007), we describe the literature review process as follows.

\subsection{Material collection}

Given the limited number of studies on Reverse Logistics of Hazardous Waste (RLHW), this study aims to cover all articles in this research area, including journal articles, conference proceedings and book chapters from January 1990 to September 2020. The literature search was conducted among the articles written in English in the Web of Science (WOS) databases. The four stages of the research procedure are as follows:

- In the first stage, the keywords "hazardous-waste reverse logistics" was used in the searching subjects of (title, abstract and keywords, respectively) and a total of 47 articles were retrieved from research databases. Besides this, since industrial hazardous waste, medical waste and electronic waste belong to hazardous waste, keywords such as "industrial hazardous-waste reverse logistics" and "medical waste reverse logistics" along with "E-waste reverse logistics" were also used for a continuous search, and 8 articles, 44 articles, and 76 articles were retrieved respectively from a string of three keywords searches mentioned above. After a careful examination, we selected 38, 2, 5, and 32 articles from four searches based on their relevance to the topic in a rather intuitive manner intuitively. 


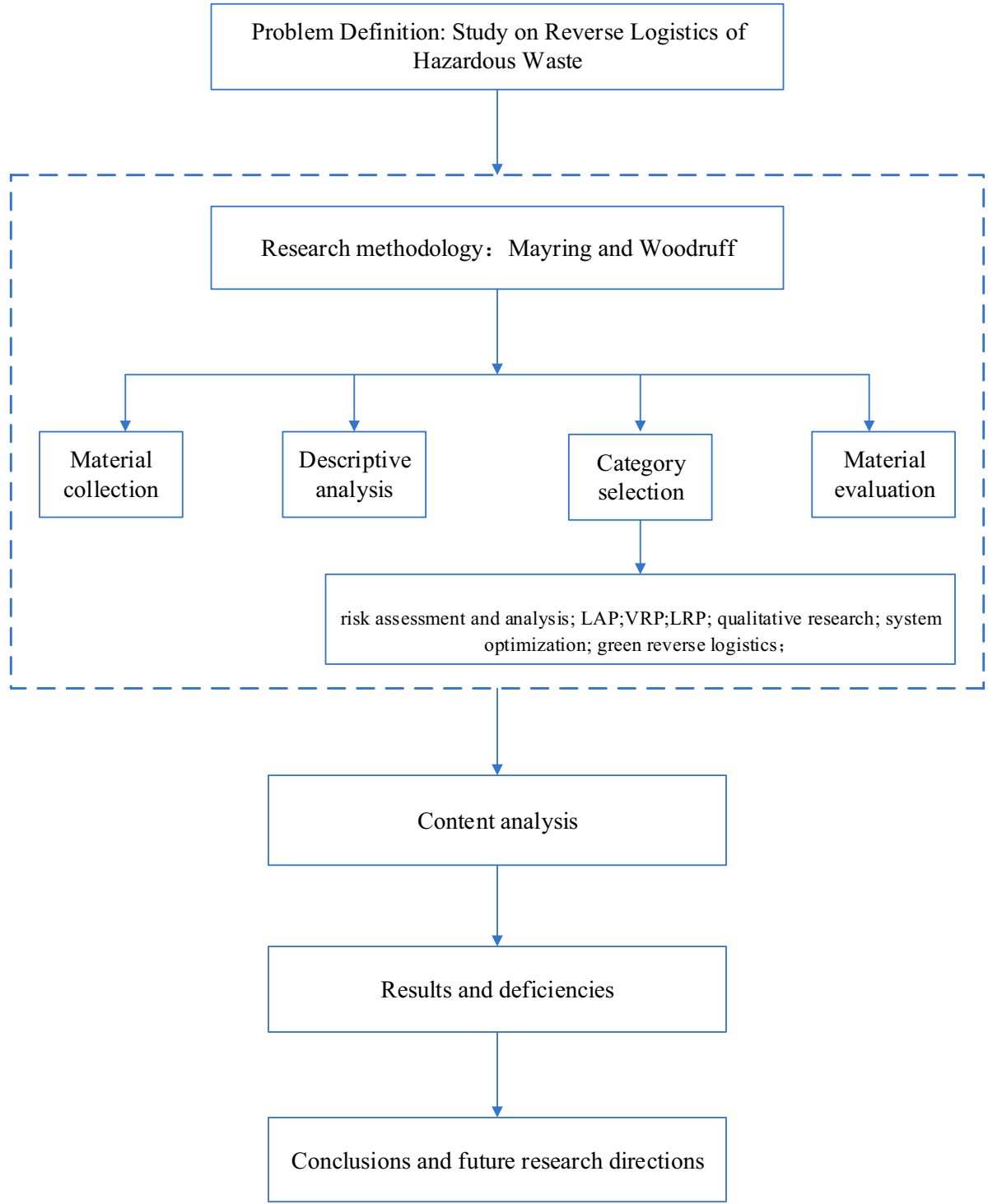

Fig. 1 The research protocol for this paper

- To ensure coverage of all articles in the field of Reverse Logistics of Hazardous Waste, in the second stage, we relaxed the keywords used in the first stage. Specifically, keywords "hazardous waste"," industrial hazardous waste"," medical waste" and "E-waste" were used in the searching subjects of title, abstract and keywords to carry articles in the Web of Science (WOS) databases. A total of 21,692, 9017, 41,227, 3049 articles were retrieved from four keywords searches, respectively.

- Considering a large number of articles collected in the second stage, we further classified the search in the third stage. Several essential keywords, such as "network design"," 
risk assessment and analysis", "location-allocation", "collection and transportation", "vehicle routing", "location-routing", "system optimization", and "green reverse logistics", were employed to refine the articles retrieved before. We also performed multiple iterations of several important keywords and the detailed number of articles refined by each keyword is given in Table 1.

- It is obvious that a narrow and refined search may result in the loss of valuable literature, so in the fourth stage, we used HistCite software to analyse the literature in the field to ensure that all significant papers are included in the study.

Following the four stages discussed above, a total of 810 papers were retrieved and 443 papers were finally identified and subsequently analysed for the purpose of this study. The publication and distribution for those 443 articles are presented in Table 2.

\subsection{Descriptive analysis}

A basic descriptive analysis was first to run on the 443 articles to provide multiple perspectives on the research structure. Figure 2 illustrates an annual distribution of the number of articles published in the stipulated time period stated before, which shows that the research in RLHW has recently received increasing attention.

The number of articles published by each journal chosen is shown in Fig. 2, and the major journal distribution of the publications is shown in Table 3, which shows that the studies were published in various journals. Six noteworthy of these journals that have published more than 7 articles in this research area were Waste Management (45 articles), Waste Management \&Research (38 articles), Journal of Cleaner Production (23 articles), Resources, Conservation, and Recycling (18 articles), Journal of Environmental Management and Journal of Material Cycles and Waste Management.

\subsection{Category selection}

Based on the criteria discussed above, the articles are classified into seven categories. The first category includes risk assessment and analysis. The location-allocation problems, vehicle routing problems, location routing problems, qualitative research, and system optimization problems are included in categories 2, 3, 4, 5 and 6 respectively. In addition, there is an increasing trend in the research on green and sustainable logistics (Carter \& Easton, 2011; Min \& Kim, 2012; Srivastava, 2007). Thus, we discuss green reverse logistics in category 7. And the distribution of the number of articles in various categories is illustrated in Fig. 3, which obviously shows that most studies focus on qualitative research, while fewest studies examined the vehicle routing problem.

\subsection{Material evaluation}

This study uses deductive and inductive approaches simultaneously to ensure the reliability of the literature review. The utilization of tables and figures also increases the illustration of the analytical results. Additionally, we cross-checked the articles by searching various databases such as Elsevier and Emerald, which enhanced the span of this review study (Table 4). 


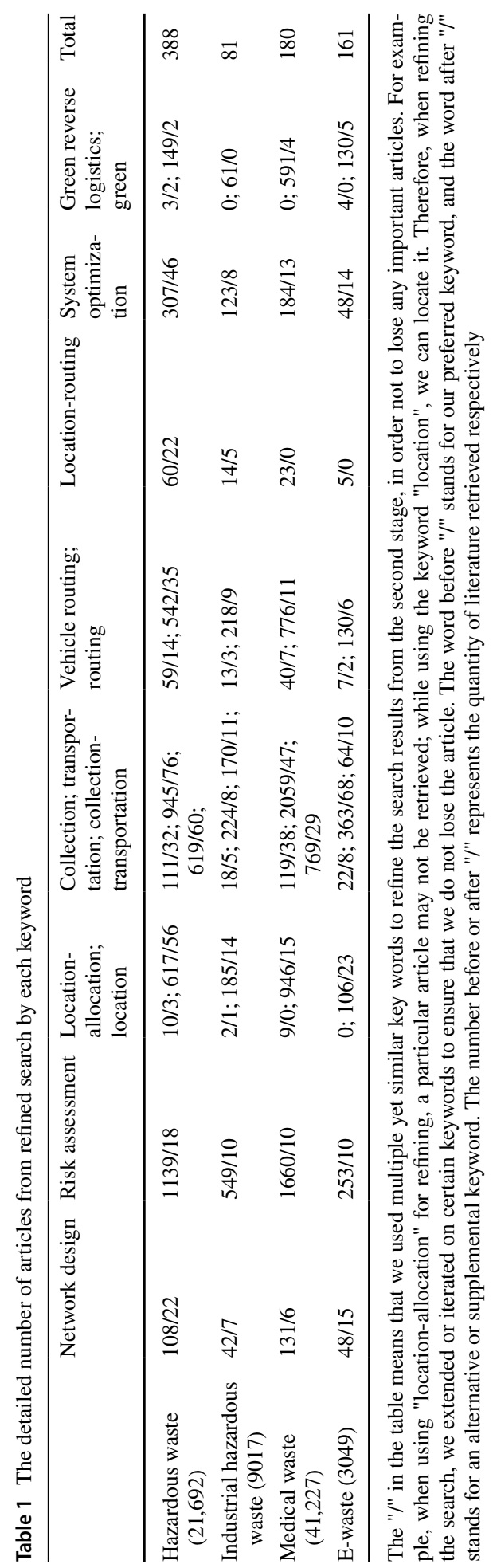


Table 2 Number of papers published in journals and conferences

\begin{tabular}{|c|c|c|}
\hline Serial number & Journals and magazines & $\begin{array}{l}\text { Number } \\
\text { of articles }\end{array}$ \\
\hline 1 & Waste Management & 47 \\
\hline 2 & Waste Management \& Research & 41 \\
\hline 3 & Journal of Cleaner Production & 29 \\
\hline 4 & Resources, Conservation and Recycling & 18 \\
\hline 5 & Journal of Environmental Management & 12 \\
\hline 6 & Journal of Material Cycles and Waste Management & 9 \\
\hline 7 & Environmental Science and Pollution Research & 6 \\
\hline 8 & Risk Analysis & 6 \\
\hline 9 & Computers \& Operations Research & 4 \\
\hline 10 & European Journal of Operational Research & 6 \\
\hline 11 & Journal of Hazardous Materials & 4 \\
\hline 12 & Journal of The Air \& Waste Management Association & 4 \\
\hline 13 & Annals of Operations Research & 5 \\
\hline 14 & Environment international & 5 \\
\hline 15 & Environmental Monitoring and Assessment & 3 \\
\hline 16 & Expert Systems with Applications & 3 \\
\hline 17 & Journal of Environmental Health Science and Engineering & 4 \\
\hline 18 & Practice Periodical of Hazardous Toxic and Radioactive Waste Management & 3 \\
\hline 19 & Transportation Research Part E and D & 4 \\
\hline 20 & Transportation Science & 3 \\
\hline 21 & Applied Mathematical Modeling & 2 \\
\hline 22 & BMC Public Health & 2 \\
\hline 23 & Environmental pollution & 4 \\
\hline 24 & Environmental Science \& Technology & 2 \\
\hline 25 & International Journal of Environmental Health Research & 3 \\
\hline 26 & International journal of environmental research and public health & 7 \\
\hline 27 & Environmental Earth Sciences & 2 \\
\hline 28 & Journal of Environmental Protection and Ecology & 2 \\
\hline 29 & Journal of urban planning and development & 2 \\
\hline 30 & Safety Science & 2 \\
\hline 31 & Transportation Research Procedia & 2 \\
\hline 32 & Conference & 74 \\
\hline \multirow[t]{2}{*}{33} & Others (1 papers) & 123 \\
\hline & Total & 443 \\
\hline
\end{tabular}

\section{Detailed analysis of the content}

In this section, a comprehensive analysis of the selected articles mentioned in Sect. 2 is provided to construct an integrated perspective of the recent studies on RLHW. The findings will shed light on the current deficiencies and future research.

The content will be classified into seven categories listed as follows: 


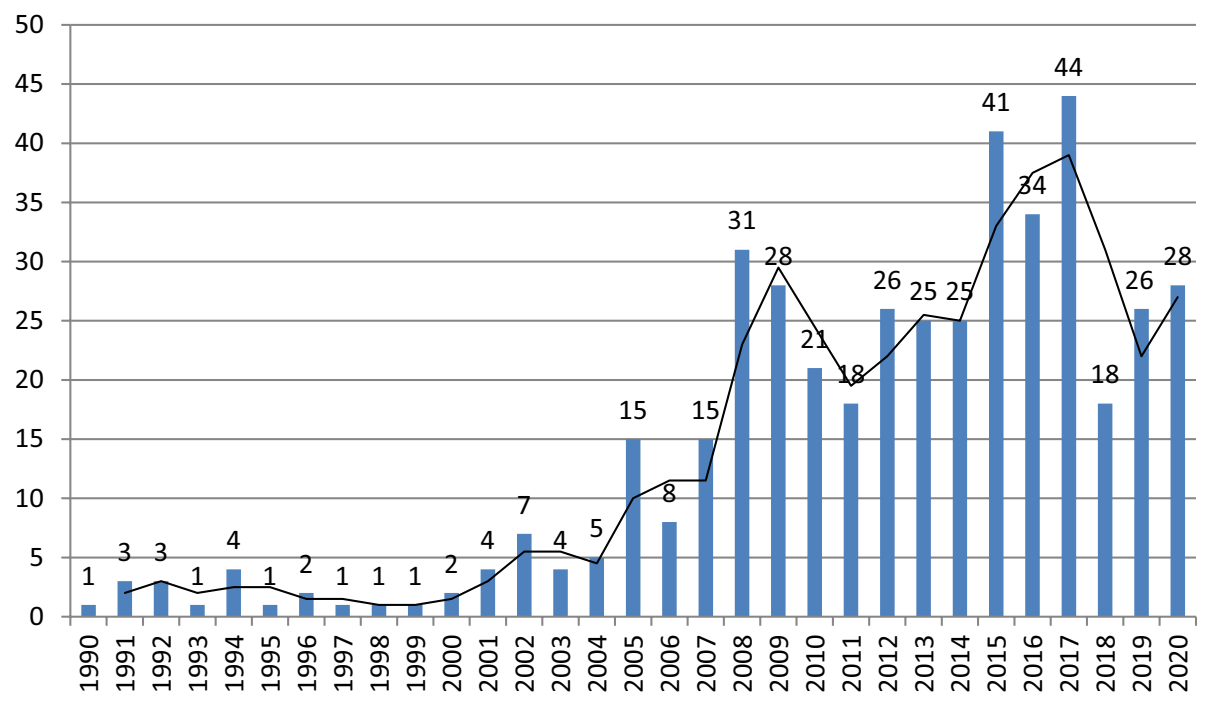

Fig. 2 Distribution of annual publications across the study (443 papers: 1990-2020)

(1) Risk assessment and analysis.

It is critical to conduct a risk assessment and analysis on RLMHW as it is a key factor in better management of hazardous waste (Scott, 1987). Therefore, this study discusses issues in risk assessment and analysis on RLMHW from two aspects, namely risk assessment in the transportation process and risk assessment in the management process.

(2) Location-allocation problem.

The reverse logistics network location problem is part of a large category of research topics. The main purpose of this type of problems is to determine long-term strategic plans such as facility function design, facility location (number and position) and facility scale. A general location-allocation problem considers these factors at the same time. Since the number of objective functions varies in the location-allocation problem, this study classifies this problem into three classes, i.e., multi-objective problems, single-objective problems and other location problems at a technical level.

(3) Vehicle routing problem.

The vehicle routing problem (VRP) has been a popular research topic since it was proposed by Dantzig and Ramser (1959). It is considered as a vital issue in the optimization process of the reverse logistics system (Shih \& Chang, 2001), since the collection-delivery system, along with related strategies, is the most effective part of the logistics network. Given that uncertainty is one of the main characteristics in reverse logistics networks, this study classifies the VRP into two groups, i.e., VRP with uncertainty and VRP with certainty. Asefi and Maghrebi (2019) formulated a mixed-integer linear programming to address the integrated solid waste management problem, and the near-optimal solutions were achieved by a heuristic solution approach.

(4) Location-routing problem.

Here, the location-routing problem (LRP) is defined as a "location problem that considers routing", with special cases, such as only considering the location problem and only considering the routing problem, which is consistent with the definition of 


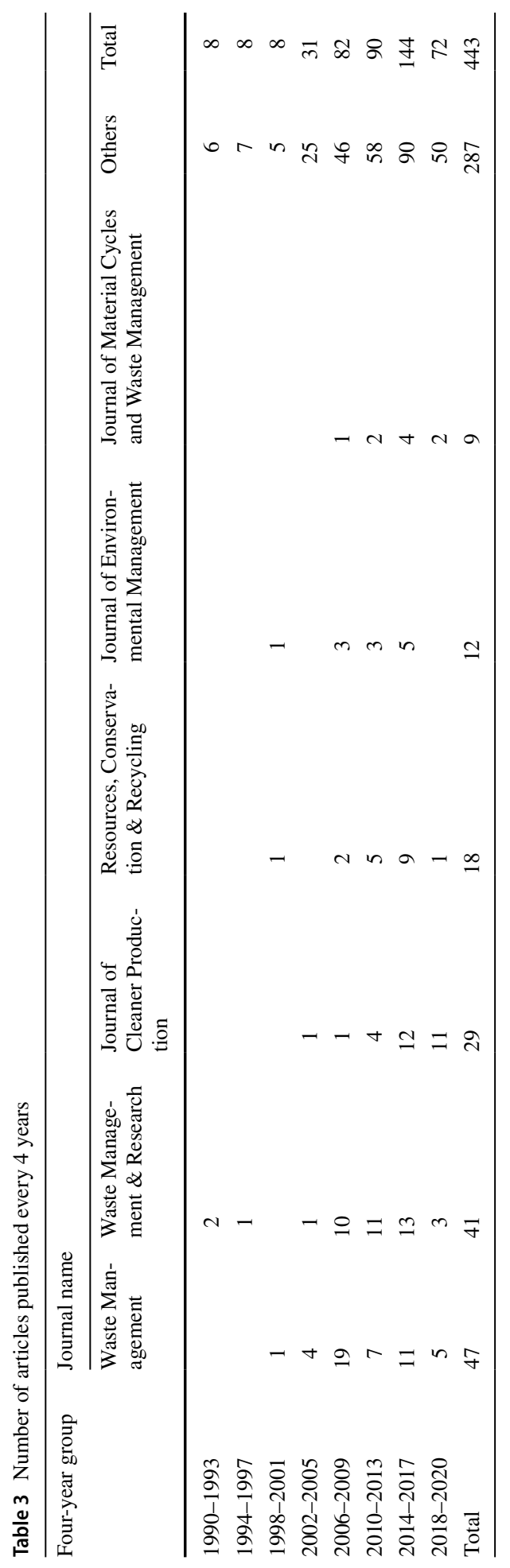


Fig. 3 Distribution of research articles for different categories (443 papers: 1990-2020)

\begin{tabular}{llll}
\hline Step & 1 & 2 & 3 \\
\hline Used database & $\begin{array}{c}\text { Web of Science (WOS); } \\
\text { google scholar database }\end{array}$ & $\begin{array}{c}\text { HistCite } \\
\text { software }\end{array}$ & $\begin{array}{c}\text { Elsevier; } \\
\text { Emer- } \\
\text { ald }\end{array}$ \\
Searched papers & 74,985 & 880 & 443 \\
\hline
\end{tabular}

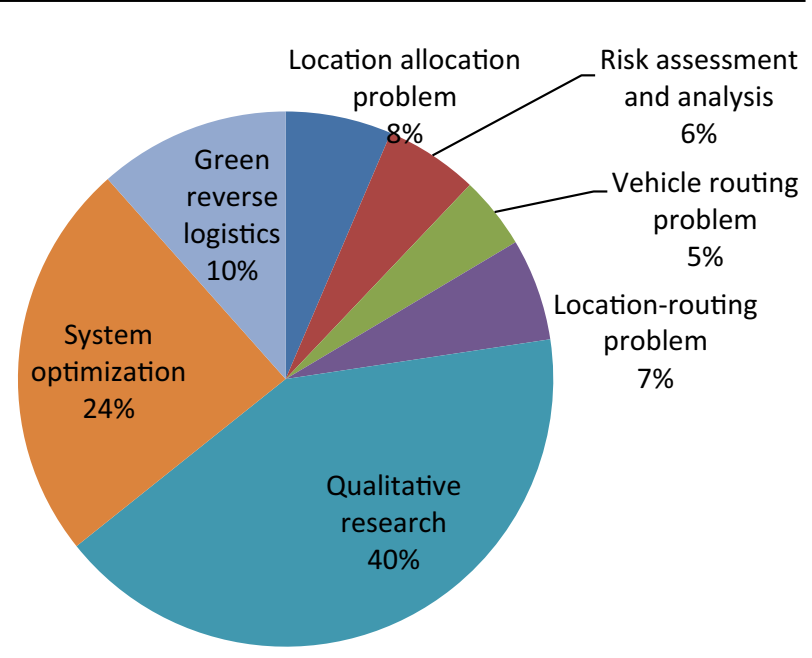

Table 4 Electronic databases 
An increasing number of studies have focused on green reverse logistics, where moral judgment and responsibility are involved. Hence, this study analyses green reverse logistics problems from the viewpoint of social responsibility and green sustainability, respectively.

\subsection{Hazardous waste risk assessment and analysis}

Risk assessment and analysis of RLMHW have been conducted in the transportation and system management process. We found more studies that explore risk assessment in the management process of RLMHW.

\subsubsection{Risk assessment in the transportation process}

Macgregor et al. (1994) were the first to assess the Oregon public to the perceived risk of radioactive waste transportation, and they also made some recommendations on the safe transport and management of radioactive waste. Later, Brainard et al. (1996) conducted a risk assessment of aqueous waste cargo transport using the consignment note records collected by the London Waste Regulation Authority during the 1980s. Other data included a road network, resident population, vehicle accident probabilities, and groundwater vulnerabilities. A GIS model was proposed to predict hazardous waste routing and evaluate the potential impacts of such movements. Comparisons and a discussion of four different routing scenarios were provided according to simulations. Lovett et al. (1997) further highlighted the application of GIS in the risk analysis by focusing on liquid hazardous waste transport. The simulation results implied that routing controls could lead to risk mitigation in hazardous waste movement. However, the risk assessment frameworks in two studies rely heavily on how the probability of the occurrence of an event is calculated. Different from the previous two studies, Das, Gupta, and Mazumder (2012a, 2012b, 2012c) designed a risk assessment framework that considering the impact on a population in offsite transportation of volatile and inflammable waste. A composite accident index was used to replace the traditional probability-based variable to evaluate risks. Their study provided an effective way to reduce risks in offsite transportation.

\subsubsection{Risk assessment in the management process}

Initially, Atlas (2001) and Pusch et al. (2002) assessed the risks posed by the storage, treatment, and disposal of hazardous wastes, and determined whether such risky facilities were distributed in ethnic or low-income areas, and they provided recommendations to maximize the environment equity. Afterwards, many scholars conducted risk assessment and investigation on the management process of hazardous waste through certain analytical methods or models, so as to understand the weak links in the management process and design improvement plan (Mohanty \& Codell, 2004; Ajdari et al., 2009; Garrick et al., 2010; Külahc1, 2011; Zhang et al., 2012; Li et al., 2012; Das, Gupta, \& Mazumder, 2012a, 2012b, 2012c).

Several studies performed risk management assessments in the field of healthcare, which creating a risk assessment framework in medical waste management by selecting medical institutions for case studies (Neveu \& Matus, 2007; Ferreira \& Teixeira, 2010; Chen \& Xiong, 2012; Liao \& Ho, 2014; Akpieyi et al., 2015; Makajic-Nikolic et al., 2016).

Furthermore, Ahluwalia and Nema (2007) proposed an integer linear programming model based on multi-time step optimization material flow to evaluate the risk of computer 
waste transportation, and finally they used Monte Carlo simulation to solve the uncertainty of waste production.

\subsection{Network location allocation problem of hazardous waste reverse logistics}

\subsubsection{Multi-objective location problems}

The disposal of hazardous waste is done in what is considered "undesirable" facilities since they have an undesirable effect on the environment and health (Plastria, 1996), which turns many location-allocation problems in hazardous-waste reverse logistics into multiobjective problems, where objectives such as economic efficiency, environmental risks, equity and administrative ease are examined simultaneously. Koo et al. (1991) utilized the waste resources allocation program and fuzzy set theory to develop multi-objective planning for the siting of a central treatment facility. The planning technique was applied to the location selection in southwestern Korea. Later, Erkut and Neuman (1992) and Rakas et al. (2004) developed a multi-objective mixed-integer program for locating undesirable facilities, where the authors considered the trade-offs among three objectives consisting of minimizing the cost of locating facilities, minimizing opposition to the facilities, and minimizing disutility on any individual. Additionally, the authors generated a set of efficient solutions using the enumeration algorithm and CPLEX method, respectively. Yong et al. (2007) designed a multi-type hazardous-waste reverse logistics network with fuzzy multiple objectives consisting of cost reduction and risk mitigation. A hybrid genetic algorithm was used to solve the network problem. Rabbani et al. (2019) proposed a novel industrial hazardous waste management model and considered three aspects of locating, vehicle routing, and inventory control.

Medical waste disposal is also considered to be done at undesirable facilities. Ulukan and Kop (2009) established a model to minimize adverse effects and minimized costs for the location of medical waste disposal facilities, where adverse effects were represented by distances, and a modified model of Ishii's algorithm was proposed to obtain a list of candidate points. Meanwhile, to construct a hospital waste management network, Medaglia et al (2009) formulated a facility location problem with two objectives: reducing the total operating cost and decreasing the negative impact on the population residing near the facility. A multi-objective evolutionary algorithm with a mixed-integer program was developed in their study to solve the facility location related problem.

In addition, radioactive waste, as one type of serious hazardous waste, can have a severe impact on the environment and health if the disposal sites are not properly located. List et al. (2006) proposed a two-stage stochastic programming model under uncertainty to analyse the transport of radioactive waste from weapon factories to disposal sites.

\subsubsection{Single-objective location problems}

Instead of multi-objective models, some location-allocation problems are investigated by formulating a single-objective program. Some scholars have established single objective mathematical models to minimize the distance between hazardous waste disposal and predetermined entities, or to minimize the global repulsion of people living in the associated region. And they all used certain methods to determine the location of hazardous waste disposal facilities (Akgül, 1994; Fernández et al., 2000). Unlike the above two scholars, Song et al. (2013) proposed a genetic algorithm to solve the models and perform sensitivity 
analysis. To explore hazardous medical waste management improvement in Portugal, De Almeida ( 2010 ) proposed mixed-integer linear programming to select the optimal location of facilities and the allocation of waste between various disposal sites in terms of cost. The authors considered two different scenarios, where the first one assumed no existing facilities and then found the best locations, while the second focused on the incinerator locations. Recently, Li et al. (2015a, 2015b) laid emphasis on Chinese industrial hazardous waste, used integer program method, and selected the optimal locating approach to the collecting and handling of industrial hazardous waste on the basis of covering location model, and conducted the model verification for Hebei Province.

\subsubsection{Location problem at a technical level}

The location problem at a technical level refers to the problem of location-allocation for hazardous waste storage, collection, treatment, and disposal facilities. A summary of the location problem at a technical level study is presented in Table 5.

In order to determine the location of hazardous waste disposal sites, many scholars have proposed different optimization models and methods for site selection and considered environmental factors in the problem (Wyman \& Kuby, 1995; Yesilnacar \& Cetin, 2005; Kanoun et al., 2013). Malik et al. (2015) studied the location problem of collection sites of the e-waste reverse logistics and used the Graph Theory and Matrix Approach (GTMA) to find the location of collection sites and used the case to verify the method. Tuzkaya et al. (2008) and Yuksel (2009) addressed the problem of undesirable facility and the e-waste collection centre location selection using the analytic network process (ANP) and analysed the validity and sensitivity of the results. Later, Andarani and Budiawan (2015) and Chauhan and Singh (2016) all studied the location of e-waste and medical waste using the same method.

Furthermore, many scholars have studied the location of hazardous waste based on GIS technology. Some have combined multi-objective decision analysis methods (De Feo \& De Gisi, 2014; Moghaddas \& Namaghi, 2011; Sauri-Riancho et al., 2011; Wilson et al., 2016).

\subsection{Vehicle routing problem of hazardous waste reverse logistics}

The vehicle routing problem (VRP for short) as a field of study and practice, has been broadly defined (Eksioglu et al., 2009). This section classifies collection and transportation system optimization issues of hazardous waste reverse logistics as a part of VRP.

\subsubsection{Deterministic problem}

Many scholars have studies the VRP of hazardous waste reverse logistics in the deterministic setting. Rahkonen et al. (1992) launched a systematic investigation of different working situations and equipment for hazardous waste collection and transport using statistical data. Several deficiencies in work safety were found. Later, in view of none of the studies have considered the depot, Zhao and Zhu (2016) designed a multi-depot vehicle-routing model for explosive waste recycling with the minimizations of total cost and total risk. A modified lexicographic-weighted Tchebycheff method was proposed to solve this multi-objective problem. Recently, Dotoli and Epicoco (2017) proposed a methodological technique for solving vehicle routing problems of hazardous waste collection and disposal, while 


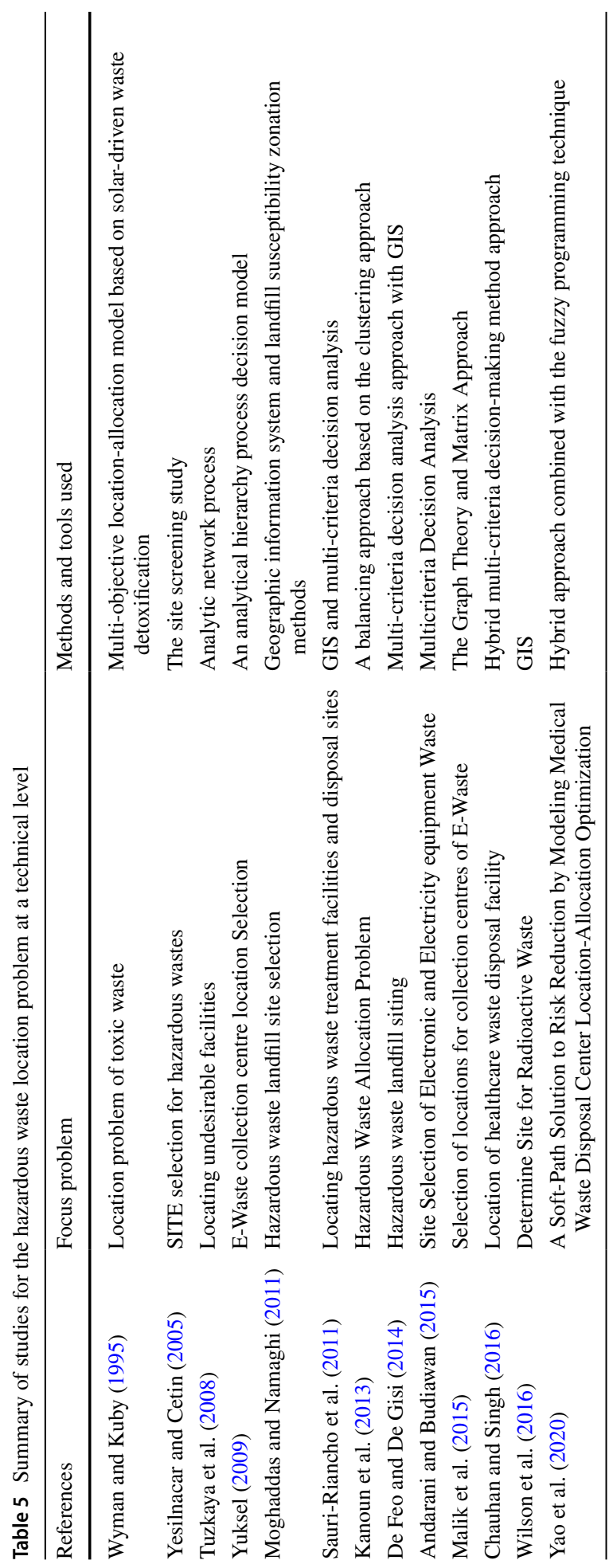


minimizing costs and emissions, and demonstrating the effectiveness of the method with real-life examples, without considering the risk objective.

Additionally, scholars have investigated how to transport hazardous wastes. Alagöz and Kocasoy (2008a, 2008b) developed a healthcare waste collection and transportation system for İstanbul, Turkey. The system considered many deterministic factors, and they conducted cost-benefit analyses of both the existing and proposed optimum transportation routes and determined the most feasible routes from the viewpoint of efficiency and economy. Shanmugasundaram et al. (2012) demonstrated the use of freeware GIS modelling tools for healthcare waste management in Laos. In this paper, spatial analysis is utilized to identify the spatial distribution of healthcare waste and optimal route models that were designed for collecting and transporting healthcare waste. Michlowicz (2012) proposed a non-linear optimization model for medical waste transport to minimize transportation and handling costs, unfortunately, leaving the risk factors untouched. Thus, Hejrani and Ko (2013) solved the problem of the collection and transportation of medical waste by establishing a multi-objective mixed-integer programming model, which also considers cost and risk to find the optimal collection and recovery decision in medical waste management networks. They applied a genetic algorithm to choose the optimal transportation route. Then, Hachicha et al. (2014) studied the transportation of medical waste in 12 hospitals in Tunisia and simulated it as a capacity-limited vehicle routing problem (CVRP) and solved it in actual case studies using CPLEX 9.0. Recently, Hajar et al. (2018) researched and optimized the route of medical waste from the point of production to the temporary storage point and established a multi-objective model that considered a time window to make a more rational route. Liu (2011) designed a nationwide hazardous campus waste collection system in Taiwan and utilized two clustering methods to simulate three different alternatives. Based on the carbon emission standards, Pasukphun (2015) designed a collection and transport route of municipal solid waste through a case study. Suggestions were provided on the amount of recovery time and the selection of collection sites.

\subsubsection{Uncertain problem}

Different from the design of deterministic problems in the previous subsection, many more scholars have been investigating the VRP of hazardous waste reverse logistics by constructing uncertain problems.

To address the routing and scheduling problems in medical waste collection system planning, Shih and Lin (2003) considered both the costs and risks of collection and transport under dynamic conditions and established an integer-based linear programming model to minimize transportation costs and risks. A compromise programming method was adopted to solve and use examples for verification. Budak and Ustundag (2013) developed a mixed-integer linear programming model under uncertain conditions to establish an efficient collection and treatment system for medical waste. They determined the optimal number and location of facilities by minimizing the total cost so that medical waste can be efficiently collected and processed. Considering the lack of specialized historical accident databases, Das et al. (2016) presented a composite approach to compute the accident index to assess accidents and risks in a network. Finally, a case study of the Kolkata Metropolitan Area was validated. Nolz et al. (2011) used RFID technology to optimize the collection and transportation of infectious medical waste and designed a tabu search-based algorithm to optimize the access date and determined the corresponding vehicle route. Similar to the above study, Alshraideh and Qdais (2017) 
established a stochastic and route scheduling model for medical waste transportation with a time window to minimize transportation costs and reduce emissions.

For the vehicle routing problem of e-waste, Nowakowski et al. (2018) studied the e-waste vehicle routing problem in the case of uncertain demand and solved it using artificial intelligence methods which they finally applied to the actual case.

\subsection{Location-routing problem of hazardous waste reverse logistics}

Nagy and Salhi (2007) classified the methods for solving location-routing problems into exact algorithms and heuristic algorithms.

\subsubsection{Exact algorithm}

For nuclear hazardous waste, Revelle et al. (1991) created a multi-objective locationrouting model, which simultaneously considered the two objectives of minimum transportation costs and minimum perceived risks. The integration method of the shortest path and the zero-one integer program was used to solve this problem. Accordingly, List and Mirchandani (1991) considered the maximization of risk equity and the minimization of cost and risk in another model, which was solved with a dynamic programming method. Later, Jacobs and Warmerdam (1994) and Giannikos (1998) proposed a multiobjective optimization model for the location-routing problem of a single type of hazardous waste and used the penalty function, and FORTMP optimizer to solve the model. Distinguished from previous studies, there are some researchers proposed a comprehensive location-routing model that considered multiple types of hazardous waste and compatibility first respectively. And they applied a linear solution to solve the model (Nema \& GzaraGupta, 1999; Alumur \& Kara 2007; Zhao \& Zhao, 2010). In order to establish a safer hazardous waste management system, Aydemir-Karadag established a hazardous waste location-routing model that maximizes the overall profitability of the system; the cost involves all aspects from the collection, recycling to disposal. And they applied the model to the actual case in Turkey and used the CPLEX software to solve the problem based on GIS technology.

Subsequently, Aboutahoun (2012) presented a mathematical model that simultaneously locates multiple disposals or treatment facilities and determining a route for the hazardous waste transportation network, and the goal was to minimize the transport distance and reduce the passing population, and finally, the author solved it using the Floyd Warshall algorithm. Yilmaz et al. (2017) developed a conceptual model, which considered waste classes, waste management principles, and waste-to-technology compatibilities. And the effectiveness of the model was verified by the Turkey case.

In an allusion to industrial hazardous waste, Boyer et al. (2013), Samanlioglu (2013) and Zhao and Verter (2015) all established a multi-objective model that considered risk and solved it using the CPLEX software package. Rabbani et al. (2019) proposed a novel industrial hazardous waste management model which considered locating, vehicle routing, and inventory control. 


\subsubsection{Heuristic algorithm}

Zografros and Samara (1990) proposed the hazardous waste siting-routing problem. An integer target programming model was established, which considered three objectives: minimizing transport risk, transport time and disposal risk. The Sperry UNIV AC/ FMPS mixed integer programming method was used to solve the problem. For "undesirable facilities", Stowers and Palekar (1993) and Cappanera et al. (2003) established a siting model for "undesirable facilities" that considered routes, to minimize the total risk, and a local search algorithm and Lagrange relaxation constraint method were applied to the model solution respectively. Later, Asgari et al. (2017) studied the location and routing problem of obnoxious waste, established a multi-objective model that considered three objectives simultaneously and used the taboo algorithm to solve the model and proved the effectiveness of the algorithm. Rabbani et al. (2017) addressed a new industrial hazardous waste location-routing problem and designed two more efficient and faster Genetic Algorithms.

In addition, some scholars have established multi-objective programming models for the location-routing of hazardous waste. And they all used the modified $\varepsilon$-constraint method to solve the model (Yu \& Solvang, 2016; Zhao et al., 2016). Zhao and Huang (2019) formulated the hazardous waste network design problem as a bi-objective mixed integer linear programming model. Rabbani et al. (2020) researched a novel multiobjective industrial hazardous waste model, which was solved by three multi-objective evolutionary algorithms. Wu et al. (2020) also established a priority considered green vehicle routing model and a hybrid algorithm was utilized to solve the model.

Multi-objective programming models for the location-routing of hazardous waste can be also found in the literature. And all those studies applied the modified $\varepsilon$-constraint method to solving the model (Yu \& Solvang, 2016; Zhao et al., 2016). A periodic loaddependent capacitated vehicle routing problem was studied and a decomposition based heuristic algorithm was designed (Taslimi et al., 2020).

Based on the fuzzy theory, Zhang and Zhao (2011) studied the treatment centre allocation, technology adoption and vehicle routing problem of hazardous waste under an uncertain condition where the waste generation amount is fuzzy. Based on theuncertainty of demand and risk, Berglund and Kwon (2014) studied the treatment centre allocation, technology adoption and vehicle routing problem of hazardous waste under an uncertain condition where the waste generation amount is fuzzy. Based on the uncertainty of demand and risk, Berglund and Kwon (2014) studied the location of hazardous waste facilities and transport routes. A mixed-integer goal programming model with a single cost objective was established, and a genetic algorithm was used to solve the large-scale data experiments. Afterward, according to the demand uncertainty, Ghezavati and Morakabatchian (2015) developed a multi-objective location-routing model, which is a real case related to the Petrochemical Special Economic Zone located in Khuzestan (Iran). Their mode had considered fuzzy customer satisfaction and was resolved by using Lingo software. Yu et al. (2020) proposed a novel stochastic biobjective mixed integer linear program to reduce the population exposure to risk and maintain a high cost efficiency of the transportation and treatment of hazardous waste. Homayouni and Pishvaee (2020) designed a collection and disposal network of hospital wastes under uncertain condition, and the total cost of transportation and operations costs, and the total risk of transportation and operations were minimized. 


\subsection{Hazardous waste qualitative research}

Overall, the qualitative research has conducted in this study via in-depth interviews and surveys, case study, focus group or other formals. Customers, companies, and their stakeholders/actors associated with the HWRL activities are included in the respondents.

The cardinal concept about this segment of the study is to obtain an idea of the previous literature review in the sphere of reverse logistic and to elucidate the demand of existing study. It examined 18 salient articles that have been promulgated on hazardous waste and reverse logistic literature reviews, as yet. These prominent literature reviews are classified and analyzed into 5 categories, concentrated on problems like, medical waste/ health-care waste/ hazardous hospital wastes (Ali et al., 2017a, 2017b; Khan \& Cheng, 2019), hazardous wastes (Anderton et al., 1994; Ceccarini et al., 2017), household hazardous waste (Inglezakis \& Moustakas, 2015), electronic waste/WEEE (Herat \& Agamuthu, 2012; Awasthi et al., 2016a, 2016b; Awasthi et al., 2018; Ciocoiu et al., 2016; Doan et al., 2019; Ilankoon et al., 2018; Islam et al., 2020; Islam \& Huda, 2018; Pérezbelis et al., 2015; Qu et al., 2013; Song \& Li, 2014; Song et al., 2017), and campus hazardous waste (Liu, 2011).

Through the analysis of this kind of literature, we find out: (1) the most concerned issue is the related activities of medical waste reverse logistics, followed by E-waste; (2) the methods most frequently used by scholars in the study are interviews, questionnaires, descriptive analysis, and field surveys; (3) another significant problem is that most countries are developing countries, among them, headed by China, India and Iran. China generates approximately 8 billion tons per annum, of which around 40 million to 60 million are hazardous waste (CSY, 2020). The Associated Chamber of Commerce of India has to gauge a $25 \%$ compound annual growth rate of waste electronic and electrical equipment (WEEE) (ASSOCHAM, 2014). It indicates that problems related to hazardous waste in developing countries are particularly serious, which must be paid more attention.

\subsection{System optimization of hazardous waste reverse logistics}

In the literature on hazardous-waste reverse logistics network research, some do not include either location-routing problems or combinatorial optimization problems, so these articles are grouped as system optimization problems. The study subdivides this type of problem into two classes: the management system optimization problem and the reverse logistics system optimization problem.

\subsubsection{Optimization of management system}

The improper handling and disposal of hazardous waste threaten human health and the environment. Thus, the optimization of hazardous waste management systems is crucial throughout the entire reverse logistics process. Alidi $(1992,1996)$ developed an integer goal programming model and a multi-objective optimization model that considers the multiple goals and needs of many groups involved in managing and planning hazardous waste systems and offers policy-makers relevant decisions. Later, in order to evaluate the hazardous waste management system and analyse the existing problems and challenges preferably, the scholars have proposed some decision methods, and established relevant models to optimize management system(Asari \& Sakai, 2011; Court et al., 2015; Gu et al., 2014; Gumus, 2009; Hernandez \& Uddameri, 2008; Hollister, 2002; Mmereki et al., 2014; 
Nema \& Gupta, 2003; Onan et al., 2015; Rerat et al., 2013). And there are some scholars to optimize the management system based on technologies such as RFID and GIS (Lu et al., 2012).

Furthermore, e-waste has attracted the attention of many scholars because of its greatest potential for recovery and value. Scholars focused on the collection and recycling of e-waste, and consider the impact of e-waste on human health and the environment, and conducted in-depth analysis and discussion on the issues to draw conclusions and make recommendations (White et al., 2003; Ahluwalia \& Nema, 2007; Achillas et al., 2010a, 2010b; Bernstad et al., 2011; Özkır et al., 2015; Li et al., 2015a, 2015b; Cesaro et al., 2017; Ikhlayel, 2017).

The efficient management of medical waste has a significant influence on the economic benefits and safety benefits of the entire society. Therefore, an increasing number of scholars have started to study the management of medical waste. Regarding medical waste, scholars mostly analysed it from the aspects of separation, collection, storage, recycling, and disposal. Then optimized and improved the entire system through qualitative analysis and quantitative research methods, and proposed suggestions and strategies for the sustainable development of medical waste management system (Alagöz \& Kocasoy, 2008a, 2008b; Birpınar et al., 2009; Chaerul et al., 2008; Longe, 2012; Marinković et al., 2008; Mentzelou et al., 2009; Mmereki et al., 2017; Rolewicz-Kalińska, 2016; Sawalem et al., 2009; Tsakona et al., 2007; Voudrias \& Graikos, 2014; Walery, 2014). Recently, Ghasemzadeh et al. (2021) developed a mixed-integer linear programming model to minimize Eco-indicator 99 (environmental index) in the supply chain network of tires in order to improve environmental conditions concerned with waste tires.

In the above studies, the authors basically conducted actual case investigations on the current medical waste management strategies and status of medical institutions and proposed suggestions and methods for different issues.

\subsubsection{Optimization of the reverse logistics system}

Based on different types of hazardous waste, Chen et al. (2008) established a multi-objective geographic information system to study the transportation route selection of nuclear waste. However, the risk was not considered in the model. Later, Sheu (2007) presented a coordinated reverse logistics (CRL) management system for the treatment of multi-source hazardous waste in a given region. A linear multi-objective analytical model was formulated to systematically minimize both the total reverse logistics operating costs and corresponding risks. Zhao and Ke (2017) recently incorporated inventory risks into a location-routing model for explosive waste management. An optimization model minimizing total cost and risk was developed to achieve the overall optimization of the explosive waste reverse logistics system. Parkitny et al. (2017) studied the collection and disposal of hazardous waste from the source to ensure the shortest route and ensure ecological safety. For the hazardous and explosive waste recovery and treatment process, Dinler and Güngör (2017) proposed a fuzzy multi-objective linear programming model and used Monte Carlo simulation to solve the Pareto optimal solution of the model, and applied the model to the factory.

Because e-waste has the highest reclamation value in the waste stream, many scholars have studied the reverse logistics of e-waste from different perspectives. First of all, some scholars have conducted research and analysis on computer equipment waste and established models to minimize the impact of cost and environmental risks (Shih, 2001; 
Ahluwalia \& Nema, 2006). Second, there are some papers, based on the technical level, such as GIS, to optimize the electronic waste reverse logistics system, so as to realize the visualization and dynamic real-time management of e-waste logistics (Tao, 2008; Jiange, 2008). What's more, in response to e-waste recycling and network design issues, some scholars have established mixed-integer programming models and multi-objective model to minimize risk and cost, thereby optimized the reverse logistics network (Gamberini et al., 2010; Chen, Sheu and Lirn, 2010; Achillas et al., 2010a, 2010b; Gomes et al., 2011; Achillas et al., 2012; Kilic et al., 2015; Ayvaz et al., 2015; Fernando \& Jorge, 2015). None of the above studies considered uncertainty. Based on this, Ahluwalia and Nema (2011), Yu and Solvang (2016), Polat et al. (2018) proposed a randomly mixed-integer programming model and a new decision method for the design and optimization of e-waste reverse logistics under uncertainty conditions. And a multi-standard two-stage solving method based on the scene was used to generate the optimal solution for stochastic optimization problems. And last, in addition to the above research on e-waste, there are many studies that mainly proposed models to optimize the collection, recycling and disposal of e-waste, or proposed a reverse logistics network model for e-waste and solved it using some methods and technique. Some scholars also analysed the factors affecting the reverse logistics activities of e-waste and the current challenges, and made recommendations (Shrivastava et al., 2005; Mou et al., 2006; Lehtinen \& Poikela, 2006; Yin, 2008; Wei \& Zhang, 2008; Gamberini et al., 2009;Efendigil et al., 2012; Phuc et al., 2013; Yeh \& Xu, 2013; Shokohyar \& Mansour, 2013; Zeng et al., 2015; Elbadrawy et al., 2015; Capraz et al., 2015; Xia et al., 2016; Tesfaye et al., 2017; John et al., 2018).

To reduce the effects of medical waste on the public and the environment, Mantzaras and Voudrias (2017) developed a non-linear optimization model, which MapInfo was used to find the best locations and shipping routes for processing facilities and trans-shipment. Recently, Liu and Yao (2018) analysed the problems in the process of medical waste transfer, established a medical waste transfer model based on RFID technology, and considered social, environmental and economic benefits in the model comprehensively. There are scholars who have also analysed and studied the characteristics of medical waste, the impact on the environment and the cost of reverse logistics (Pereir et al., 2017; Liu \& Yao, 2017; Walery, 2017). Liu et al. (2020) adopted the immune algorithm-ant colony optimization-tabu search (IA-ACO-TS) algorithm to solve the medical waste disposal problem in the emergent public health event of COVID-19.

\subsection{Hazardous waste green reverse logistics}

In recent years, green reverse logistics has received increasing attention on an international scale (Messmann et al., 2020). Given the increasing popularity and importance of green sustainable supply chain management, this section will provide the research status on the sustainable reverse logistics of hazardous waste from the aspects of social responsibility and green sustainable development.

\subsubsection{The aspect of social responsibility}

Studies in healthcare hazardous waste management have revealed social responsibility as a critical factor. With regard to medical waste, scholars analysed and investigated the factors affecting the classification, collection, storage, and discharge of medical waste. The quality, 
cognitive attitude, level of hospital staff, and related management personnel are the important factors. Therefore, based on the problems and challenges, the scholars put forward corresponding suggestions (Abdulla et al., 2008; Caniato et al., 2016; Da Silva et al., 2005; Miyazaki et al., 2007; Otto et al., 2018).

The management of household hazardous waste (HHW) has been widely studied in the literature from the perspective of social responsibility. Families and residents are important members of the community, and there are many types of hazardous waste generated by households, including toxic e-waste, medical waste, and other wastes that can harm the environment and human health. Based on this, many scholars have investigated and studied the family and residents' participation in household hazardous waste collection and recycling, and concluded and made targeted recommendations (Slack et al., 2009; Elston, 2010; Wagner et al., 2013; Inglezakis \& Moustakas, 2015; Lim-Wavde et al., 2016; Lim-Wavde et al., 2017; Ndayizigamiye et al., 2017).

Social responsibility has also been studied in other types of hazardous waste such as e-waste and retailing waste. Some scholars had conducted a survey and research on the participation of consumers and residents in the collection and recycling of e-waste, and analysed the factors affecting the participation in waste recycling, and made corresponding suggestions (Dixit \& Badgaiyan, 2016; Nixon et al. 2007; Saphores et al., 2012). Besides, many scholars focused on the management of electrical and electronic equipment waste (WEEE), and they studied the impact of Extended Producer Responsibility (ERP) implementation on WEEE management and reverse logistics of e-waste. The involvement of recycling operators, social economy companies and others could contribute to WEEE management (Khetriwal et al., 2009; Kojima et al., 2009; Neto \& Van Wassenhove, 2013; Yoon \& Jang, 2006; Zoeteman et al., 2010). Noting the increase of hazardous waste in the retail industry, Triantafyllou and Cherrett (2010) suggested producers and distributors take more responsibility for the collection and treatment of hazardous waste to increase environmental safety. The authors studied 92 businesses in terms of hazardous waste logistics and explored the coordination of hazardous waste management across supply chains.

\subsubsection{The aspect of green sustainability}

Most studies associated with a sustainable environment focused on WEEE and medical waste. The management and recycling of WEEE, one of the largest waste streams, has played a crucial role in environmental sustainability. Therefore, many scholars focused on the collection and recycling of e-waste, combined with life cycle methods and material flow analysis methods to study the collection and recovery system of e-waste and point out the main problems in each link through case studies and descriptive analysis. And finally, they proposed corresponding improvement strategies (Bakhiyi et al., 2017; Cole et al., 2018; De Souza et al., 2016; Gamberini et al., 2008; Hischier et al., 2005; Kahhat et al., 2008; Maheswari et al., 2018; Tanskanen, 2013). Other scholars had also studied the process of collection, disassembly, recycling, and disposal of e-waste from the perspective of economic, social and environmental sustainability (Gehin et al., 2008; Vadoudi et al., 2015; Dhib et al., 2015; Ilankoon et al., 2018). And a few studies can be found in areas such as air pollution standards, environmental equity, and end-of-life vehicle management (Emek \& Kara, 2007; Anderton et al., 1994; Lara et al., 2017; Simic \& Dimitrijevic, 2019).

Inappropriate treatment of infectious healthcare waste in developing countries has made a non-negligible impact on public health and environment safety. Diaz et al. (2005) explained and discussed some treatment and disposal methods commonly used in 
developing counties. Bdour et al. (2007) surveyed medium to large healthcare facilities in the northern Jordan concerning medical waste management. Various methods such as waste segregation and linking TARI tax to waste generation were suggested in the study. Anthony et al. (2020) discussed the potential impact of green IS infrastructure on reducing overall use of hazardous materials.

\section{Discussion on the results, deficiency and implications}

This section summarizes the analysis of the literature in Sect. 3, evaluates the sub-research areas already studied most, outlines the deficiencies of the current studies, and provides practical and theoretical implications.

In Sect. 3, the research on RLHW is classified into seven categories. Figure 4 shows how those research categories interact with each other. Analytical methods (including exact algorithms and heuristic algorithms) are mainly applied in solving for LAP, VRP and LRP problems, where LRP can be considered as a combination of LAP and VRP. The research objectives in System optimization are more complex, and accordingly, the research methodology is more diverse. Both analytical and qualitative methods have been applied in the area of System optimization. Besides, more innovative research methods can be explored in this area. Due to the lack of clear formulation in the area of Green reverse logistics, qualitative methods are mostly applied for analysis. System optimization is believed to overlap with Green reverse logistics. More research conducted in Green reverse logistics will lead to more improvement in the area of System optimization, and more extensive managerial insights to RLHW industry and related areas.

Figure 5 demonstrates the distribution of studies in each sub research area. Several observations in Fig. 5 are listed as follows: (1) most current articles study on qualitative research and optimization of reverse logistics, while fewer papers study "risk assessment in management process, uncertain VRP, LRP with uncertainty, LRP with Heuristic algorithm and objective location problem"; (2) uncertain factors are not considered in risk assessment; (3) in the area of location-allocation problems, many studies focus on technique

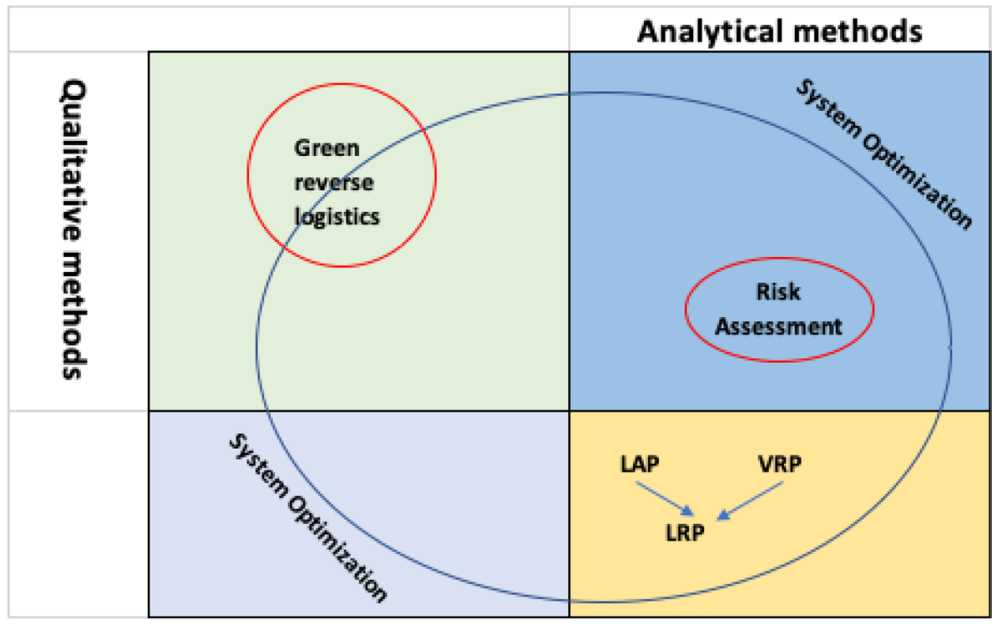

Fig. 4 Relationship between research categories reviewed in Sect. 3 
level, while there is less focus on the multiple objectives; (4) in vehicle routing problems no article has studied the time window; (4) in location-routing optimization problems fewer studies use heuristic methods; (5) fewer studies on the location-routing optimization problem consider uncertain circumstances; (6) in the area of system optimization, a similar number of studies examine reverse logistics system optimization and management system optimization; and (7) in the area of green reverse logistics, a similar number of studies are found that consider the aspects of society responsibility and sustainable development. We further discuss the detailed deficiencies in various categories.

(1) The deficiency of research on uncertainty

This study classifies all the literature into six categories. A limited number of papers discuss uncertainty in each category. In Fig. 5, we can see the number of papers in each category that considers uncertainty. To solve uncertain problems, most studies use fuzzy theory or two-stage stochastic methods. Koo et al. (1991), Rakas et al. (2004), Erkut and Neuman (1992), and Ghezavati and Morakabatchian (2015) all used fuzzy theory to analyse the multi-objective model and determine the weight for each objective. Yin (2008), Gumus (2009) adopted two-stage stochastic methods to study the uncertainty problem. Additionally, Sun et al. (2017) used the robust optimization technique to solve an uncertain problem. Furthermore, in the system of RLHW, there are many uncertain factors, such as weather, road conditions, potential population exposure and production of hazardous waste. Rabbani et al. (2019) adopted a multi-objective evolutionary algorithm to solve a real-size optimization problem under uncertainty.

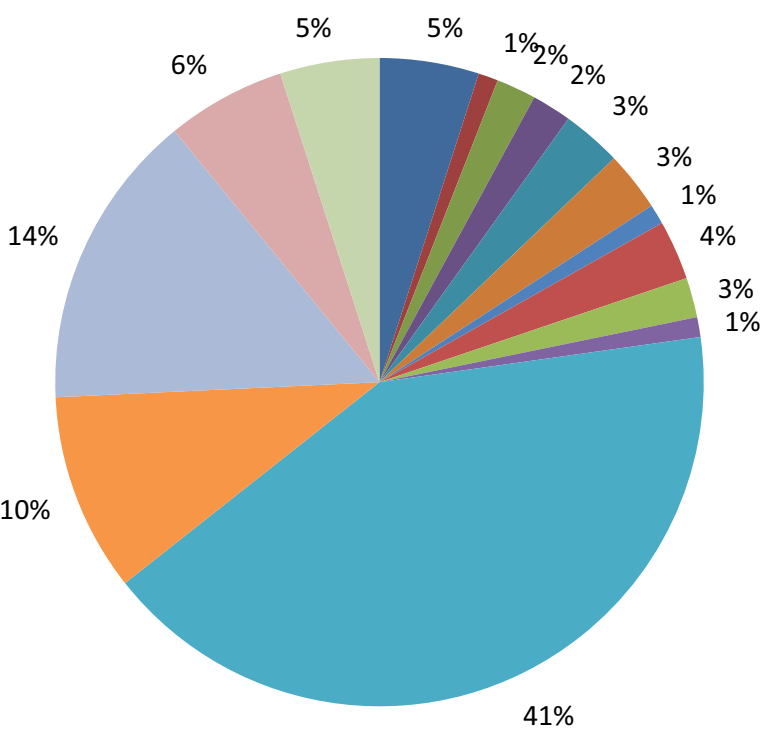

Fig. 5 Number of sub-field studies (443 papers: 1990-2020)
Risk assessment in the transportation process

Risk assessment in management process

Multi-objective location problem

- Single-objective location problem

Location problem with technical level

Deterministic VRP

Uncertain VRP

LRP with Exact Algorithm

LRP with Heuristic algorithm

LRP with uncertainty

Qualitative research

Optimization of Management System

Optimization of Reverse Logistics System 
From the above, we can see that there are still many deficiencies in research on uncertainty.

(2) The deficiency of solution techniques

Many solution methods have been adopted to solve problems in RLHW. Some researchers attempted to implement an analytical method, but this is complex and has limited effects on solving large-scale problems (Nagy \& Salhi, 2007). Some researchers used a general analytical solver such as Lingo, GAMS or CPLEX. For large scale problems, researchers adopted the heuristic method and hyper-heuristic methods, such as genetic algorithms, ant colony algorithms, Tabu search algorithm or mixed algorithms. Simulation techniques and software are usually implemented for solving uncertain problems. Many algorithms have been used to solve multi-objective programming's, such as goal optimization, AHP, and TOPSIS. There are deficiencies in the applications of heuristic methods. Stowers and Palekar (1993) used a local search algorithm; Habib et al. (2016) used the Tabu search-Ant colony algorithm, and Rabbani et al. (2017) used an improved genetic algorithm.

There should be a reasonable connection between the modelling method and its solution algorithm (Gupta Govindan, Soleimani, \& Kannan, 2015). Our analysis shows that there is no reasonable connection between the model design and solution algorithm in RLHW activities.

(3) The deficiency of single/multi-objective

In the modelling process, economic, environmental and social benefits should be considered and quantified at the same time (Wang et al., 2011). Hazardous waste management has been recognized as one of the main environmental problems in this era (Goel, 2017). Environmental sustainability becomes more and more important worldwide, especially in developing countries (Gupta \& Palsule-Desai, 2011). Although many studies in Sect. 3 have considered multiple objectives, there are still deficiencies in the decision-making and modelling of a multi-objective analysis compared to those of a single objective analysis. To easily solve the problem, most studies have simplified the model, which makes them less practical.

(4) The deficiency of consideration with the vehicle type and time windows

Cao et al. (2016) classified the vehicle routing problems into two categories, i.e., single-vehicle and multi-vehicle, based on vehicle types. To simplify the problem, most studies examining hazardous waste vehicle routing problems and the LRP problem did not consider the vehicle type and set a single vehicle as default. Furthermore, time windows have been widely used in common vehicle routing problems, but no article has considered a time window in the problem of hazardous waste vehicle routing. And time windows have a significant impact on the efficiency and performance of vehicle transportation (Brandão, 2018).

(5) The deficiency of research on HW transportation network design

There are no studies on the hazardous waste transportation network design based on our classification and analysis, although there are few rich studies associated with the hazardous materials transportation network design problem, which is a gap to be filled.

(6) The deficiency of green reverse logistics

Slack et al. (2009), Triantafyllou and Cherrett (2010), Wagner et al. (2013), Inglezakis and Moustakas (2015), and Lim-Wavde et al. (2016, 2017) all analysed the current status of the collection and handled household hazardous waste from the perspective of social responsibility. However, they did not consider practical factors such as public cognition or provide a practical plan. 
(7) The deficiency of risk assessment and analysis

Among all the studies we reviewed, only three considered a risk assessment of hazardous waste under dynamic circumstances (Brainard et al., 1996; Das et al. 2012a, b, c; Lovett et al, 1997). However, those three studies did not consider any uncertain factors, which overlook major differences from the complicated reality.

Based on the discussion above, we believe that this research will serve as a stepping stone to researchers interested in domains of reverse logistics of hazardous waste management in the local context by narrowing the research gap. This study offers a snapshot of hundreds of papers at one place in solving logistical issues in domains of reverse logistics of hazardous waste materials management ranging from medical waste, household waste, nuclear waste, and WEEE. Furthermore, the research incorporates both qualitative as well as quantitative papers in an effort to allow a more balanced overview of the current status of scholarly research undertaken to unveil dichotomies in the theory and practice of RLHW. Finally, the systematic literature review protocol lays out processes to investigate whether or not there is any difference in terms of scope, interest, and efforts needed to publish research in indigenous and non-indigenous research outlets.

\section{Conclusions and future research directions}

This study provides a comprehensive review of the literature of RLHW in various academic journals. A total of 443 papers published from January 1990 to September 2020 are reviewed, classified and analysed. The findings in this study offer a better understanding of RLMHW by systematic crystallization of archival data in a systematic chronological order across central issues. This study contributes to scholarly debate in this field by serving as a snapshot paper to document the development of the field and gives input to policymakers in process design and policy making in the domain of RLMHW.

This study also reveals some future research directions for RLHW. Modification in nondeterministic approaches and integration of these methods, and regarding more uncertain parameters are identified as future opportunities in uncertain parameters. To consider optimization models under dynamic environments, a particular problem with soft or hard time windows suggests several future directions in vehicle routing problems and opportunities. On the aspect of solution methodologies, across the relationship between model and solution algorithms should be built, where a different algorithm is designed to solve each model. Additionally, heuristic and hyper-heuristic algorithms should also be adopted as important types of solution algorithms in this field. Due to the complicated reality, an increasing number of objects need to be considered together. Thus, paying more attention to multi-objective problems can be the future direction in single and multiple objective problems. In addition, the vehicle routing problem of hazardous waste and the LRP problem considering vehicle types also have good potential for future research. The network design problem of hazardous waste and the optimization of collection routes are also future directions of study.

Finally, since WEEE is one of the waste types with the highest recycle value and potential; research on e-waste is the most popular in the area of hazardous waste. Hence, research on the reverse logistics of electronic waste needs to be emphasized. Certainly, we should also lay emphasis on medical waste and other hazardous waste. In addition, it 
should be noted that the research directions listed above could be studied synthetically to attain a deeper understanding and more comprehensive results.

Funding The work was partly supported by the National Key Technology Research and Development Program of the Ministry of Science and Technology of China (No. 2015BAK39B00) and National Key Research and Development Program of the Ministry of Science and Technology of China (No. 2019YFC1906100).

\section{References}

Abdulla, F., Qdais, H. A., \& Rabi, A. (2008). Site investigation on medical waste management practices in northern Jordan. Waste Management, 28(2), 450-458.

Aboutahoun, A. W. (2012). Combined distance-reliability model for hazardous waste transportation and disposal. Life Science Journal, 9(2), 1286-1295.

Achillas, C., Aidonis, D., Vlachokostas, C., Moussiopoulos, N., Banias, G., \& Triantafillou, D. (2012). A multi-objective decision-making model to select waste electrical and electronic equipment transportation media. Resources, Conservation and Recycling, 66, 76-84.

Achillas, C., Vlachokostas, C., Aidonis, D., Moussiopoulos, N., Iakovou, E., \& Banias, G. (2010a). Optimizing reverse logistics network to support policy-making in the case of electrical and electronic equipment. Waste Management, 30(12), 2592-2600.

Achillas, C., Vlachokostas, C., Moussiopoulos, N, \& Banias, G. (2010b). Decision support system for the optimal location of electrical and electronic waste treatment plants: A case study in Greece. Waste Management, 30(5), 870-879.

Ahluwalia, P. K., \& Nema, A. K. (2006). Multi-objective reverse logistics model for integrated computer waste management. Waste Management \& Research, 24(6), 514-527.

Ahluwalia, P. K., \& Nema, A. K. (2007). A life cycle based multi-objective optimization model for the management of computer waste. Resources Conservation \& Recycling, 51(4), 792-826.

Ahluwalia, P. K., \& Nema, A. K. (2011). Capacity planning for electronic waste management facilities under uncertainty: Multi-objective multi-time-step model development. Waste Management \& Research. The Journal of the International Solid Wastes \& Public Cleansing Association ISWA., 29(7), 694-709.

Ajdari, S., Babadoost, A., Zamani, B., \& Shahriari, M. (2009). Risk evaluation of household hazardous waste: A case study. In Proceedings of international symposium on occupational safety and hygiene SHO 20 (pp. 23-27).

Akgül, M. (1994). An optimization approach for locating a hazardous waste disposal facility in Istanbul province. Waste Management \& Research, 12(6), 495-506.

Akpieyi, A., Tudor, T. L., \& Dutra, C. (2015). The utilization of risk-based frameworks for managing healthcare waste: A case study of the National Health Service in London. Safety of Science, 72, 127-132.

Alagöz, A. Z., \& Kocasoy, G. (2008a). Determination of the best appropriate management methods for the health-care wastes in Istanbul. Waste Management, 28(7), 1227-1235.

Alagöz, A. Z., \& Kocasoy, G. (2008b). Improvement and modification of the routing system for the healthcare waste collection and transportation in Istanbul. Waste Management, 28(8), 1461-1471.

Ali, M., Wang, W., Chaudhry, N., \& Geng, Y. (2017a). Hospital waste management in developing countries: A mini-review. Waste Management \& Research, 35(6), 581-592.

Ali, M., Wang, W., Chaudhry, N., Geng, Y., \& Ashraf, U. (2017b). Assessing knowledge, performance, and efficiency for hospital waste management: A comparison of government and private hospitals in Pakistan. Environmental Monitoring \& Assessment, 189(4), 181.

Alidi, A. S. (1992). An integer goal programming model for hazardous waste treatment and disposal. Applied Mathematical Modelling, 16(12), 645-651.

Alidi, A. S. (1996). A multiobjective optimization model for the waste management of the petrochemical industry. Applied Mathematical Modelling, 20(12), 925-933.

Alshraideh, H., \& Qdais, H. A. (2017). Stochastic modeling and optimization of medical waste collection in Northern Jordan. Journal of Material Cycles and Waste Management, 19(2), 743-753.

Alumur, S., \& Kara, B. Y. (2007). A new model for the hazardous waste location-routing problem. Computers \& Operations Research, 34(5), 1406-1423.

Andarani, P., \& Budiawan, W. (2015). Multicriteria decision analysis for optimizing site selection of electronic and electricity equipment waste dismantling and sorting facility (Case study: In Indonesia, 
using AHP). In 2015 international conference on science in information technology (ICSITech) (pp. 264-269). IEEE.

Anderton, D. L., Anderson, A. B., Rossi, P. H., Oakes, J. M., \& Fraser, M. R. (1994). Hazardous Waste Facilities: "Environmental Equity" Issues in Metropolitan Areas. Evaluation Review., 18(2), 123-140.

Anthony, B., Majid, M. A., \& Romli, A. (2020). Green IS diffusion in organizations: A model and empirical results from Malaysia. Environment, Development and Sustainability, 22(1), 383-424.

Asari, M., \& Sakai, S. I. (2011). Consumer perspectives on household hazardous waste management in Japan. Journal of Material Cycles \& Waste Management, 13(1), 10-24.

Asefi, H., \& Maghrebi, M. (2019). Mathematical modelling and heuristic approaches to the location-routing problem of a cost-effective integrated solid waste management. Annals of Operations Research, 237(1-2), 75-110.

Asgari, N., Rajabi, M., Jamshidi, M., Khatami, M., \& Farahani, R. Z. (2017). A memetic algorithm for a multi-objective obnoxious waste location-routing problem: A case study. Annals of Operations Research, 250(2), 1-30.

ASSOCHAM. (2014). Electronic waste management in India an Associated Chambers of Commerce of India. Retrieved 4 May 2021, from http://www.indiaenvironmentportal.org.in/files/assocham\%20pre ss\%20release.pdf.

Atlas, M. K. (2001). Safe and sorry: Risk, environmental equity, and hazardous waste management facilities. Risk Analysis, 21(5), 939-939.

Awasthi, A. K., Wang, M., Awasthi, M. K., Wang, Z. S., \& Li, J. H. (2018). Environmental pollution and human body burden from improper recycling of e-waste in China: A short-review. Environmental Pollution, 243, 1310-1316.

Awasthi, A. K., Zeng, X. L., \& Li, J. H. (2016a). Relationship between e-waste recycling and human health risk in India: A critical review. Environmental Science and Pollution Research, 23(12), 11509-11532.

Awasthi, A. K., Zeng, X. L., \& Li, J. H. (2016b). Comparative examining and analysis of e-waste recycling in typical developing and developed countries. In 5th international conference on solid waste management (IconSWM) (Vol. 35, pp. 676-680).

Ayvaz, B., Bolat, B., \& Aydın, N. (2015). Stochastic reverse logistics network design for the waste of electrical and electronic equipment. Resources, Conservation, and Recycling, 104, 391-404.

Bakhiyi, B., Gravel, S., Ceballos, D., Flynn, M. A., \& Zayed, J. (2017). Has the question of e-waste opened a Pandora's box? An overview of unpredictable issues and challenges. Environment International, $110(1), 173-192$.

Bdour, A., Altrabsheh, B., Hadadin, N., \& Al-Shareif, M. (2007). Assessment of medical wastes management practice: A case study of the northern part of Jordan. Waste Management, 27(6), 746-759.

Berglund, P. G., \& Kwon, C. (2014). Robust facility location problem for hazardous waste transportation. Networks and Spatial Economics, 14(1), 91-116.

Bernstad, A., Jansen, J. L., \& Aspegren, H. (2011). Property-close source separation of hazardous waste and waste electrical and electronic equipment: A Swedish case study. Waste Management, 31(3), 536-543.

Birpınar, M. E., Bilgili, M. S., \& Erdoğan, T. (2009). Medical waste management in Turkey: A case study of Istanbul. Waste Management, 29(1), 445-448.

Boyer, O., Hong, T. S., Pedram, A., Yusuff, R. B. M., \& Zulkifli, N. (2013). A mathematical model for the industrial hazardous waste location-routing problem. Journal of Applied Mathematics, 2013: 435272.

Brainard, J., Lovett, A., \& Parfitt, J. (1996). Assessing hazardous waste transport risks using a GIS. International Journal of Geographical Information Systems, 10(7), 831-849.

Brandão, J. (2018). Iterated local search algorithm with ejection chains for the open vehicle routing problem with time windows. Computers \& Industrial Engineering, 120(Jun), 146-159.

Budak, A., \& Ustundag, A. (2013). A risk analysis of waste collection and disposal in health institutions of Turkey. In Intelligent systems and decision making for risk analysis and crisis response-proceedings of the 4th international conference on risk analysis and crisis response, RACRpp (pp. 657-663).

Caniato, M., Tudor, T. L., \& Vaccari, M. (2016). Assessment of health-care waste management in a humanitarian crisis: A case study of the Gaza Strip. Waste Management, 58, 386-396.

Cao, J., Chen, Y., Shi, B., Lu, B., Zhang, X. M., Ye, X. H., Zhai, G. S., Zhu, C. B., \& Zhou, G. G. (2016). WEEE recycling in Zhejiang Province, China: Generation, treatment, and public awareness. Journal of Cleaner Production, 127, 311-324.

Cappanera, P., Gallo, G., \& Maffioli, F. (2003). Discrete facility location and routing of obnoxious activities. Discrete Applied Mathematics, 133(1), 3-28.

Capraz, O., Polat, O., \& Gungor, A. (2015). Planning of waste electrical and electronic equipment (WEEE) recycling facilities: MILP modeling and case study investigation. Flexible Services \& Manufacturing Journal, 27(4), 1-30. 
Carter, C. R., \& Easton, P. L. (2011). Sustainable supply chain management: Evolution and future directions. International Journal of Physical Distribution \& Logistics Management, 41(1), 46-62.

Ceccarini, A., Bianchi, F., Minichilli, F., Fazzo, L., Santoro, M., DellaSeta, M., Comba, P., \& Martuzzi, M. (2017). Hazardous waste and health impact: A systematic review of the scientific literature. Environmental Health, 16(1), 1-11.

Cesaro, A., Belgiorno, V., Vaccari, M., Jandric, A., \& Chung, T. D. (2017). A device-specific prioritization strategy based on the potential for harm to human health in informal WEEE recycling. Environmental Science and Pollution Research, 25(1), 683-692.

Chaerul, M., Tanaka, M., \& Shekdar, A. V. (2008). Resolving complexities in healthcare waste management: A goal programming approach. Waste Management \& Research, 26(3), 217-232.

Chauhan, A., \& Singh, A. (2016). A hybrid multi-criteria decision-making method approach for selecting a sustainable location of healthcare waste disposal facility. Journal of Cleaner Production, 139, 1001-1010.

Chen, X. Y., \& Xiong, H. B. (2012). The analysis of identification and prevention for the environmental risk from incineration for medical wastes. In Proceedings of the 4th international conference on environmental technology and knowledge transfer (pp. 397-402).

Chen, Y. W., Wang, C. H., \& Lin, S. J. (2008). A multi-objective geographic information system for route selection of nuclear waste transport. Omega, 36(3), 363-372.

Ciocoiu, C. N., Colesca, S. E., RudäfReanu, C., \& Popescu, M. L. (2016). Management of waste electrical and electronic equipment in Romania: A mini-review. Waste Management \& Research, 34(2), 96-106.

Cole, C., Gnanapragasam, A., Singh, J., \& Cooper, T. (2018). Enhancing reuse and resource recovery of electrical and electronic equipment with reverse logistics to meet carbon reduction targets. In 25th CIRP life cycle engineering (LCE) conference.

Court, C. D., Munday, M., Roberts, A., \& Turner, K. (2015). Can the hazardous waste supply chain 'hotspots' be identified using an input-output framework? European Journal of Operational Research, 241(1), 177-187.

CSY. (2020). China statistical yearbook. China Statistical Publishing House.

Da Silva, C. E., Hoppe, A. E., Ravanello, M. M., \& Mello, N. (2005). Medical wastes management in the south of Brazil. Waste Management, 25(6), 600-605.

Dantzig, G. B., \& Ramser, J. H. (1959). The truck dispatching problem. Management of Science, 6(1), 80-91.

Das, A., Gupta, A. K., \& Mazumder, T. N. (2012a). A comprehensive risk assessment framework for offsite transportation of inflammable hazardous waste. Journal of Hazardous Material, 227-228, 88-96.

Das, A., Gupta, A. K., \& Mazumder, T. N. (2012b). Vulnerability assessment using hazard potency for regions generating industrial hazardous waste. Journal of Hazardous Materials, 229, 308-317.

Das, A., Mazumder, T. N., \& Gupta, A. K. (2012c). Pareto frontier analyses based decision-making tools for transportation of hazardous waste. Journal of Hazardous Materials, 227, 341-352.

Das, A., Mazumder, T. N., \& Gupta, A. K. (2016). A methodology to design a composite accident index and assess the links in a network carrying hazardous waste: A case study of Kolkata Metropolitan area. In 11th international conference on transportation planning and implementation methodologies for developing countries (TPMDC) (Vol. 17, pp. 273-281).

De Feo, G., \& De Gisi, S. (2014). Using MCDA and GIS for hazardous waste landfill siting considering land scarcity for waste disposal. Waste Management, 34(11), 2225-2238.

De Souza, R. G., Clímaco, J. C. N., Sant'Anna, A. P., Rocha, T. B., do Valle, R. A., \& Quelhas, O. L. (2016). Sustainability assessment and prioritization of e-waste management options in Brazil. Waste Management, 57, 46-56.

Dhib, S., Addouche, S. A., Mhamdi, A. E, \& Loukil, T. (2015). Performance study for a sustainable strategy: Case of electrical and electronic equipment's waste. In IFIP international conference on product lifecycle management (Vol. 467, pp. 572-587). Springer International Publishing.

Diaz, L. F., Savage, G. M., \& Eggerth, L. L. (2005). Alternatives for the treatment and disposal of healthcare wastes in developing countries. Waste Management, 25(6), 626-637.

Dinler, E., \& Güngör, Z. (2017). Planning decisions for recycling products containing hazardous and explosive substances: A fuzzy multi-objective model. Resources, Conservation and Recycling. https://doi. org/10.1016/j.resconrec.2016.11.012

Dixit, S., \& Badgaiyan, A. J. (2016). Towards an improved understanding of reverse logistics: Examining the mediating role of return intention. Resources Conservation \& Recycling, 107, 115-128.

Doan, L. T. T., Amer, Y., Lee, S. H., Phuc, P. N. K., \& Dat, L. Q. (2019). E-waste reverse supply chain: A review and future perspectives. Applied Sciences-Basel, 9(23), 5195. 
Dotoli, M., \& Epicoco, N. (2017). A vehicle routing technique for hazardous waste collection. In 20th world congress of the international-federation-of-automatic-control (IFAC) (Vol. 50 (1), pp. 9694-9699).

Efendigil, T., Ozkir, V., Demirel, N.C., Demirel, T., \& Ondemir, O. (2012). A framework proposal upon the estimation of electronic: Waste products in Istanbul. In Uncertainty modeling in knowledge engineering and decision making (pp. 1184-1189).

Eksioglu, B., Vural, A. V., \& Reisman, A. (2009). The vehicle routing problem: A taxonomic review. Computers \& Industrial Engineering, 57(4), 1472-1483.

Elbadrawy, R., Moneim, A. F. A., \& Fors, M. N. (2015). E-waste reverses logistics optimization in Egypt. In International conference on industrial engineering and operations management (pp. 1-6). IEEE.

Elston, H. J. (2010). When household hazardous waste is too hazardous: A case study. Journal of Chemical Health \& Safety, 17(4), 12-15.

Emek, E., \& Kara, B. Y. (2007). Hazardous waste management problem: The case for incineration. Computers \& Operations Research, 34(5), 1424-1441.

Erkut, E., \& Neuman, S. (1992). A multi-objective model for locating undesirable facilities. Annals of Operations Research, 40(1), 209-227.

Fernández, J., Fernández, P., \& Pelegrın, B. (2000). A continuous location model for siting a non-noxious undesirable facility within a geographical region. European Journal of Operational Research, 121(2), 259-274.

Fernando, A. S., \& Jorge, M. (2015). Cost assessment and benefits of using RFID in reverse logistics of waste electrical \& electronic equipment (WEEE). Procedia Computer Science, 55, 688-697.

Ferreira, V., \& Teixeira, M. R. (2010). Healthcare waste management practices and risk perceptions: Findings from hospitals in the Algarve region, Portugal. Waste Management, 30(12), 2657-2663.

Gamberini, R., Gebennini, E., \& Grassi, A. (2008). An innovative model for WEEE recovery network management in accordance with the EU directives. International Journal of Environmental Technology and Management, 8(4), 348-368.

Gamberini, R., Gebennini, E., Manzini, R., \& Ziveri, A. (2010). On the integration of planning and environmental impact assessment for a WEEE transportation network: A case study. Resources, Conservation and Recycling, 54(11), 937-951.

Gamberini, R., Gebennini, E., \& Rimini, B. (2009). An innovative container for weee collection and transport: Details and effects following the adoption. Waste Management, 29(11), 2846-2858.

Garrick, B. J., Stetkar, J. W., \& Bembia, P. J. (2010). Quantitative risk assessment of the New York stateoperated west valley radioactive waste disposal area. Risk Analysis, 30(8), 1219-1230.

Gehin, A., Zwolinski, P., \& Brissaud, D. (2008). A tool to implement sustainable end-of-life strategies in the product development phase. Journal of Cleaner Production, 16(5), 566-576.

Ghasemzadeh, Z., Sadeghieh, A., \& Shishebori, D. (2021). A stochastic multi-objective closed-loop global supply chain concerning waste management: a case study of the tire industry. Environment, Development and Sustainability, 23, 5794-5821.

Ghezavati, V., \& Morakabatchian, S. (2015). Application of a fuzzy service level constraint for solving a multi-objective location-routing problem for the industrial hazardous wastes. Journal of Intelligent \& Fuzzy Systems, 28(5), 2003-2013.

Giannikos, I. (1998). A multi-objective programming model for locating treatment sites and routing hazardous wastes. European Journal of Operational Research, 104(2), 333-342.

Goel, S. (2017). Solid and Hazardous Waste Management: An Introduction. In S. Goel (Ed.), Advances in Solid and Hazardous Waste Management. Cham: Springer. https://doi.org/10.1007/ 978-3-319-57076-1_1.

Gomes, M. I., Barbosa-Povoa, A. P., \& Novais, A. Q. (2011). Modeling a recovery network for WEEE: A case study in Portugal. Waste Management, 31(7), 1645-1660.

Greer, L. E. (1984). Definition of hazardous waste. Hazardous Waste, 1(3), 309-322.

Gu, B. X., Zhu, W. M., Wang, H. K., Zhang, R. R., Liu, M. M., Chen, Y. Q., Wu, Y., Yang, X. Y., He, S., Cheng, R., Yang, J., \& Bi, J. (2014). Household hazardous waste quantification, characterization, and management in China's cities: A case study of Suzhou. Waste Management, 34(11), 2414-2423.

Guimarães, A. G., Vaz-Fernandes, P., Ramos, M. R., \& Martinho, A. P. (2018). Co-processing of hazardous waste: The perception of workers regarding sustainability and health issues in a Brazilian cement company. Journal of Cleaner Production, 186, 313-324.

Gumus, A. T. (2009). Evaluation of hazardous waste transportation firms by using a two-step fuzzy-AHP and TOPSIS methodology. Expert Systems with Applications, 36(2), 4067-4074.

Gupta Govindan, K., Soleimani, H., \& Kannan, D. (2015). Reverse logistics and closed-loop supply chain: A comprehensive review to explore the future. European Journal of Operational Research, 240(3), 603-626. 
Gupta, S., \& Palsule-Desai, O. D. (2011). Sustainable supply chain management: Review and research opportunities. IIMB Management Review, 23(4), 234-245.

Habib, M. S., Lee, Y. H., \& Memon, M. S. (2016). Mathematical models in humanitarian supply chain management: A systematic literature review. Mathematic Problem in Engineering, 2016, 1-20. https://doi.org/10.1155/2016/3212095

Hachicha, W., Mellouli, M., Khemakhem, M., \& Chabchoub, H. (2014). Routing system for infectious healthcare-waste transportation in Tunisia: A case study. Environmental Engineering \& Management Journal, 13(1), 21-29.

Hajar, Z., Btissam, D., \& Mohamed, R. (2018). Onsite medical waste multi-objective vehicle routing problem with time windows. In 4th international conference on logistics operations management (GOL) (pp. 1-5). IEEE.

Hejrani, S., \& Ko, H. S. (2013). A reverse logistics model for medical waste management. In IIE annual conference. Proceedings. Institute of Industrial and Systems Engineers (pp. 97).

Herat, S., \& Agamuthu, P. (2012). E-waste: A problem or an opportunity? Review of issues, challenges, and solutions in Asian countries. Waste Management \& Research, 30(11), 1113-1129.

Hernandez, E. A., \& Uddameri, V. (2008). Hazardous waste assessment, management, and minimization. Water Environment Research, 80(10), 1648-1653.

Hischier, R., Wäger, P., \& Gauglhofer, J. (2005). Does WEEE recycling make sense from an environmental perspective? The environmental impacts of the Swiss take-back and recycling systems for waste electrical and electronic equipment (WEEE). Environmental Impact Assessment Review, 25(5), 525-539.

Hollister, K. A. K. (2002). A risk/cost framework for logistics policy evaluation: Hazardous waste management. The Journal of Business and Economic Studies, 8(1), 51-64.

Homayouni, Z., \& Pishvaee, M. S. (2020). A bi-objective robust optimization model for hazardous hospital waste collection and disposal network design problem. Journal of Maternal Cycles and Waste Management, 22, 1965-1984.

IARC (International Agency for Research on Cancer). (2006). IARC monographs on the evaluation of carcinogenic risks to humans: Preamble. Retrieved August 29, 2014, from http://monographs.iarc. fr/ENG/Preamble/index.php.

Ikhlayel, M. (2017). An integrated approach to establish e-waste management systems for developing countries. Journal of Cleaner Production, 170, 119-130.

Ilankoon, I., Ghorbani, Y., Chong, M. N., Herath, G., Moyo, T., \& Petersen, J. (2018). E-waste in the international context: A review of trade flows, regulations, hazards, waste management strategies and technologies for value recovery. Waste Management, 82, 258-275.

Inglezakis, V. J., \& Moustakas, K. (2015). Household hazardous waste management: A review. Journal of Environmental Management, 150, 310-321.

Islam, A., Ahmed, T., Awual, M. R., Rahman, A., Sultana, M., Abd, Aziz A., et al. (2020). Advances in sustainable approaches to recover metals from e-waste: A review. Journal of Cleaner Production, $244,118815$.

Islam, M. T., \& Huda, N. (2018). Reverse logistics and closed-loop supply chain of waste electrical and electronic equipment (WEEE)/E-waste: A comprehensive literature review. Resources, Conservation and Recycling, 137, 48-75.

Jacobs, T. L., \& Warmerdam, J. M. (1994). Simultaneous routing and siting for hazardous-waste operations. Journal of Urban Planning and Development, 120(3), 115-131.

Jiange, T. (2008). Research of E-waste reverse logistics information system based on web-GIS. In International conference on risk and reliability management (pp. 850-853).

John, S. T., Sridharan, R., \& Kumar, P. N. R. (2018). Reverse logistics network design: A case of mobile phones and digital cameras. The International Journal of Advanced Manufacturing Technology, 94(1-4), 615-631.

Kahhat, R., Kim, J., Xu, M., Allenby, B., Williams, E., \& Zhang, P. (2008). Exploring e-waste management systems in the United States. Resources, Conservation and Recycling, 52(7), 955-964.

Kanoun, I., Masmoudi, Y., Chabchoub, H., \& Aouni, B. (2013). A balanced approach for hazardous waste allocation problem. In International conference on modeling, simulation and applied optimization (pp. 1-6). IEEE.

Khan, B. A., \& Cheng, L. S. (2019). Healthcare waste management in Asian developing countries: A mini review. Waste Management \& Research, 37(9), 863-875.

Khetriwal, D. S., Kraeuchi, P., \& Widmer, R. (2009). Producer responsibility for e-waste management: Key issues for consideration-Learning from the Swiss experience. Journal of Environmental Management, 90(1), 153-165.

Kilic, H. S., Cebeci, U., \& Ayhan, M. B. (2015). Reverse logistics system design for the waste of electrical and electronic equipment (WEEE) in Turkey. Resources, Conservation and Recycling, 95, 120-132. 
Kojima, M., Yoshida, A., \& Sasaki, S. (2009). Difficulties in applying extended producer responsibility policies in developing countries: Case studies in e-waste recycling in China and Thailand. Journal of Material Cycles \& Waste Management, 11(3), 263-269.

Koo, J. K., Shin, H. S., \& Yoo, H. C. (1991). Multi-objective siting planning for a regional hazardous waste treatment center. Waste Management \& Research, 9(3), 205-218.

Külahcı, F. (2011). A risk analysis model for radioactive wastes. Journal of Hazardous Materials, 191(1), 349-355.

Lara, E. R., De la Rosa, J. R., Castillo, A. I. R., Cerino-Cordova, F. D., Chuken, U. J. L., Delgadillo, S. S. F., \& Rivas-Garcia, P. (2017). A comprehensive hazardous waste management program in a Chemistry School at a Mexican university. Journal of Cleaner Production, 142, 1486-1491.

Lehtinen, U., \& Poikela, K. (2006). Challenges of WEEE on reverse logistics: a case study on a collection network in Finland. In Proceedings of logistics research network annual conference (pp. 1-8).

Li, J., Zeng, X., Chen, M., Ogunseitan, O. A., \& Stevels, A. (2015a). "Control-alt-delete": Rebooting solutions for the E-waste problem. Environmental Science \& Technology, 49(12), 7095-7108.

Li, L., Wang, S., Lin, Y. T., Liu, W. T., \& Chi, T. (2015b). A covering model application on Chinese industrial hazardous waste management based on an integer program method. Ecological Indicators, 51, 237-243.

Li, Y., Li, J. H., Chen, S. S., \& Diao, W. H. (2012). Establishing indices for groundwater contamination risk assessment in the vicinity of hazardous waste landfills in China. Environmental Pollution, 165, 77-90.

Liao, C. J., \& Ho, C. C. (2014). Risk management for outsourcing biomedical waste disposal-using the failure mode and effects analysis. Waste Management, 34(7), 1324-1329.

Lim-Wavde, K., Kauffman, R. J., \& Dawson, G. S. (2016). Policy analytics, household informedness and the collection of household hazardous waste. In 3th international conference on industrial engineering and applications (ICIEA) (Vol. 68, pp. 1-5).

Lim-Wavde, K., Kauffman, R. J., \& Dawson, G. S. (2017). Household informedness and policy analytics for the collection and recycling of the household hazardous waste in California. Resources, Conservation and Recycling, 120, 88-107.

List, G., \& Mirchandani, P. (1991). An integrated network/planar multiobjective model for routing and siting for hazardous materials and wastes. Transportation Science, 25(2), 146-156.

List, G. F., Wood, B., Turnquist, M. A., Nozick, L. K., Jones, D. A., \& Lawton, C. R. (2006). Logistics planning under uncertainty for disposition of radioactive wastes. Computers \& Operations Research, 33(3), 701-723.

Liu, H., \& Yao, Z. (2017). The research on the recycling management model of medical waste based on RFID technology. Fresenius Environmental Bulletin, 26(12A), 469-477.

Liu, H., \& Yao, Z. (2018). Study of transfer station model for medical waste based on RFID and sensor technology. Fresenius Environmental Bulletin, 27(11), 7652-7660.

Liu, K. H. (2011). Planning for hazardous campus waste collection. Journal of Hazardous Materials, 189(1), 363-370.

Liu, Z. Y., Li, Z., Chen, W. M., Zhao, Y. P., Yue, H. X., \& Wu, Z. Z. (2020). Path optimization of medical waste transport routes in the emergent public health event of COVID-19: A hybrid optimization algorithm based on the immune-ant colony algorithm. International Journal of Environmental Research and Public Health, 17, 5831.

Longe, E. O. (2012). Healthcare waste management status in Lagos State, Nigeria: A case study from selected healthcare facilities in Ikorodu and Lagos metropolis. Waste Management \& Research, $30(6), 562-571$.

Lovett, A. A., Parfitt, J. P., \& Brainard, J. S. (1997). Using GIS in risk analysis: A case study of hazardous waste transport. Risk Analysis, 17(5), 625-633.

Lu, H. D., Fan, B. C., Yuan, L. H., \& Li, Y. N. (2012). RFID-based hazardous waste management platform establishment. Procedia Engineering, 29, 4-8.

Macgregor, D., Slovic, P., Mason, R. G., Detweiler, J., Binney, S. E., \& Dodd, B. (1994). Perceived risks of radioactive waste transport through Oregon: Results of a statewide survey. Risk Analysis, 14(1), $5-14$.

Maheswari, H., Yudoko, G., \& Adhiutama, A. (2018). Customer value chain analysis for sustainable reverse logistics implementation: indonesian mobile phone industry. In 2018 IEEE international conference on industrial engineering and engineering management (IEEM) (pp. 89-92). IEEE.

Makajic-Nikolic, D., Petrovic, N., Belic, A., Rokvic, M., Radakovic, J. A., \& Tubic, V. (2016). The fault tree analysis of infectious medical waste management. Journal of Cleaner Production, 113, 365-373. 
Malik, S., Kumari, A., \& Agrawal, S. (2015). Selection of locations of collection centers for reverse logistics using GTMA. In 4th international conference on materials processing and characterization (ICMPC) (pp. 2538-2547).

Mantzaras, G., \& Voudrias, E. A. (2017). An optimization model for the collection, haul, transfer, treatment and disposal of infectious medical waste: Application to a Greek region. Waste Management, $69,518-534$.

Marinković, N., Vitale, K., Holcer, N. J., Dzakula, A., \& Pavic, T. (2008). Management of hazardous medical waste in Croatia. Waste Management, 28(6), 1049-1056.

Mayring P., Brunner E. (2007) Qualitative Inhaltsanalyse. In: Buber R., Holzmüller H.H. (eds) Qualitative Marktforschung. Gabler. https://doi.org/10.1007/978-3-8349-9258-1_42

Medaglia, A. L., Villegas, J. G., \& Rodríguez-Coca, D. M. (2009). Hybrid biobjective evolutionary algorithms for the design of a hospital waste management network. Journal of Heuristics, 15(2), 153-176.

Mentzelou, P., Vosniakos, F., Dardavesis, T., Papadakis, N., Nikolaou, K., \& Athansiadou, C. (2009). An information system for hospital waste management. Journal of Environmental Protection \& Ecology, 10(1), 285-294.

Messmann, L., Zender, V., Thorenz, A., \& Tuma, A. (2020). How to quantify social impacts in strategic supply chain optimization: State of the art. Journal of Cleaner Production. https://doi.org/10. 1016/J.JCLEPRO.2020.120459

Michlowicz, E. (2012). Optimization of nonlinear transport-production task of medical waste. Archives of Transport, 24(3), 353-366.

Min, H., \& Kim, I. (2012). Green supply chain research: Past, present, and future. Logistics Research, 4(1-2), 39-47.

Miyazaki, M., Imatoh, T., \& Une, H. (2007). The treatment of infectious waste arising from home health and medical care services: Present situation in Japan. Waste Management, 27(1), 130-134.

Mmereki, D., Baldwin, A., Li, B. Z., \& Liu, M. (2017). Healthcare waste management in Botswana: Storage, collection, treatment, and disposal system. Journal of Material Cycles \& Waste Management, 19(1), 351-365.

Mmereki, D., Li, B., \& Meng, L. (2014). Hazardous and toxic waste management in Botswana: Practices and challenges. Waste Management \& Research, 32(12), 1158-1168.

Moghaddas, N. H., \& Namaghi, H. H. (2011). Hazardous waste landfill site selection in Khorasan Razavi Province, Northeastern Iran. Arabian Journal of Geosciences, 4(1-2), 103-113.

Mohanty, S., \& Codell, R. B. (2004). Ramifications of risk measures in implementing quantitative performance assessment for the proposed radioactive waste repository at Yucca Mountain, Nevada, USA. Risk Analysis, 24(3), 537-546.

Mou, P., Pan, X. Y., Xiang, D., \& Duan, G. H. (2006). Regional E-waste reverse logistics system based on PCB recycling unit. In IEEE international symposium on electronics and the environment (pp. 346-350).

Nagy, G., \& Salhi, S. (2007). Location-routing: Issues, models and methods. European Journal of Operational Research, 177(2), 649-672.

Ndayizigamiye, P., Hangulu, L., \& Akintola, O. (2017). A design of a mobile health intervention to enhance home-carers' disposal of medical waste in South Africa. In Global humanitarian technology conference (pp. 282-287).

Nema, A. K., \& Gupta, S. K. (2003). Multiobjective risk analysis and optimization of a regional hazardous waste management system. Practice Periodical of Hazardous, Toxic, and Radioactive Waste Management, 7(2), 69-77.

Nema, A. K., \& GzaraGupta, S. K. (1999). Optimization of regional hazardous waste management systems: An improved formulation. Waste Management, 19(7), 441-451.

Neto, J. Q. F., \& Van Wassenhove, L. N. (2013). Original equipment manufacturers' participation in takeback initiatives in Brazil: An analysis of engagement levels and obstacles. Journal of Industrial Ecology, 17(2), 238-248.

Neveu, C. A., \& Matus, C. P. (2007). Management of hazardous waste in a hospital. Revista Médica De Chile, 135(7), 885-895.

Nixon, H., Ogunseitan, O. A., Saphores, J. D., Ogunseitan, O. A., \& Shapiro, A. A. (2007). Electronic waste recycling preferences in California: The role of environmental attitudes and behaviors. In IEEE international symposium on electronics \& the environment (pp. 251-256).

Nolz, P. C., Absi, N., \& Feillet, D. (2011). Optimization of infectious medical waste collection using RFID. In 2 nd international conference on computational logistics (Vol. 6971, pp. 86-100).

Nowakowski, P., Szwarc, K., \& Boryczka, U. (2018). Vehicle route planning in e-waste mobile collection on-demand supported by artificial intelligence algorithms. Transportation Research Part d: Transport and Environment, 63, 1-22. 
Onan, K., Ulengin, F., \& Sennaroglu, B. (2015). An evolutionary multi-objective optimization approach to disaster waste management: A case study of Istanbul, Turkey. Expert Systems with Applications, 42(22), 8850-8857.

Otto, S., Kibbe, A., Henn, L., Hentschke, L., \& Kaiser, F. G. (2018). The economy of E-waste collection at the individual level: A practice-oriented approach of categorizing determinants of E-waste collection into behavioral costs and motivation. Journal of Cleaner Production, 204, 33-40.

Özkır, V. Ç., Efendigil, T., Demirel, T., Demirel, N. C., Deveci, M., \& Topcu, B. (2015). A three-stage methodology for initiating an effective management system for electronic waste in Turkey. Resources Conservation \& Recycling, 96, 61-70.

Parkitny, W., Wojcik, W., \& Generowicz, A. (2017). Logistic problem connected with removing asbestos as dangerous waste from terrains of country communes. IOP Conference Series: Earth and Environmental Science, 95(4), 1-11.

Pasukphun, N. (2015). Low carbon solid waste collection and transportation route in university: A case study. Journal of Environmental Science and Technology, 8(4), 180-187.

Pereir, A. L., Barros, R., \& Pereira, S. R. (2017). Pharmacopollution and household waste medicine (hwm): How reverse logistics is environmentally important to brazil. Environmental Science and Pollution Research, 24, 24061-24075.

Pérezbelis, V., Bovea, M., \& Ibáñezforés, V. (2015). An in-depth literature review of the waste electrical and electronic equipment context: Trends and evolution. Waste Management Research, 33(1), 3-29.

Phuc, P., Yu, V. F., \& Chou, S. Y. (2013). Optimizing the fuzzy closed-loop supply chain for electrical and electronic equipments. International Journal of Fuzzy Systems, 15(1), 9-21.

Plastria, F. (1996). Optimal location of undesirable facilities: An overview. Journal of Operations Research, Statistics and Computer Science, 36(2), 495-496.

Polat, O., Capraz, O., \& Gungor, A. (2018). Modeling of WEEE recycling operation planning under uncertainty. Journal of Cleaner Production, 180, 769-779.

Pusch, R., Popov, V., \& Adey, R. (2002). Risk assessment for hazardous waste disposal in abandoned mines. Risk Assessment for Hazardous Waste Disposal in Abandoned Mines, 5, 47-57.

Qu, Y., Zhu, Q., Sarkis, J., Geng, Y., \& Zhong, Y. G. (2013). A review of developing an e-waste collection system in Dalian, China. Journal of Cleaner Production, 52(4), 176-184.

Rabbani, M., Heidari, R., Farrokhi-Asl, H., \& Rahimi, N. (2017). Using metaheuristic algorithms to solve a multi-objective industrial hazardous waste location-routing problem considering incompatible waste types. Journal of Cleaner Production, 170, 227-241.

Rabbani, M., Heidari, R., \& Yazdanparast, R. (2019). A stochastic multi-period industrial hazardous waste location-routing problem: Integrating NSGA-II and Monte Carlo simulation. European Journal of Operational Research, 272(3), 945-961.

Rabbani, M., Nikoubin, A., \& Farrokhi-Asl, H. (2020). Using modified metaheuristic algorithms to solve a hazardous waste collection problem considering workload balancing and service time windows. Soft Computing, 25, 1885-1912.

Rahkonen, P., Mahnén, Y., \& Ettala, M. (1992). Work safety in the collection and transport of hazardous wastes. Waste Management \& Research, 10(3), 217-226.

Rakas, J., Teodorović, D., \& Kim, T. (2004). Multi-objective modeling for determining the location of undesirable facilities. Transportation Research Part D: Transport and Environment, 9(2), 125-138.

Rerat, C., Papadokonstantakis, S., \& Hungerbühler, K. (2013). Integrated waste management in the batch chemical industry based on multi-objective optimization. Journal of the Air \& Waste Management Association, 63(3), 349-366.

ReVelle, C., Cohon, J., \& Shobrys, D. (1991). Simultaneous siting and routing in the disposal of hazardous wastes. Transportation Science, 25(2), 138-145.

Rolewicz-Kalińska, A. (2016). Logistic constraints as a part of a sustainable medical waste management system. Transportation Research Procedia, 16, 473-482.

Samanlioglu, F. (2013). A multi-objective mathematical model for the industrial hazardous waste locationrouting problem. European Journal of Operational Research, 226(2), 332-340.

Saphores, J. D. M., Ogunseitan, O. A., \& Shapiro, A. A. (2012). Willingness to engage in a pro-environmental behavior: An analysis of e-waste recycling based on a national survey of U.S. households. Resources Conservation \& Recycling, 60(3), 49-63.

Sauri-Riancho, M. R., Cabañas-Vargas, D. D., Echeverría-Victoria, M., Gamboa-Marrufo, M., CentenoLara, R., \& Mendez-Novelo, R. I. (2011). Locating hazardous waste treatment facilities and disposal sites in the State of Yucatan, Mexico. Environmental Earth Sciences, 63(2), 351-362.

Sawalem, M., Selic, E., \& Herbell, J. D. (2009). Hospital waste management in Libya: A case study. Waste Management, 29(4), 1370-1375. 
Scott, M. P. (1987). Applications of risk assessment techniques to hazardous waste management. Waste Management \& Research, 5(2), 173-181.

Shanmugasundaram, J., Soulalay, V., \& Chettiyappan, V. (2012). Geographic information system-based healthcare waste management planning for treatment site location and optimal transportation routing. Waste Management \& Research, 30(6), 587-595.

Sheu, J. B. (2007). A coordinated reverse logistics system for regional management of multi-source hazardous wastes. Computers \& Operations Research, 34(5), 1442-1462.

Shih, L. H. (2001). Reverse logistics system planning for recycling electrical appliances and computers in Taiwan. Resources, Conservation, and Recycling, 32(1), 55-72.

Shih, L. H., \& Chang, H. C. (2001). A routing and scheduling system for infectious waste collection. Environmental Modeling \& Assessment, 6(4), 261-269.

Shih, L. H., \& Lin, Y. T. (2003). Multicriteria optimization for infectious medical waste collection system planning. Practice Periodical of Hazardous, Toxic, and Radioactive Waste Management, 7(2), 78-85.

Shokohyar, S., \& Mansour, S. (2013). Simulation-based optimization of a sustainable recovery network for Waste from Electrical and Electronic Equipment (WEEE). International Journal of Computer Integrated Manufacturing, 26(6), 487-503.

Shrivastava, P., Zhang, H. C., Li, J. Z., \& Whitely, A. (2005). Evaluating obsolete electronic products for disassembly, material recovery and environmental impact through a decision support system. In International symposium on electronics and the environment (pp. 221-225). IEEE Computer Society.

Simic, V., \& Dimitrijevic, B. (2019). End-of-life vehicle management: a survey of logistics network design models[R]. In Proceedings of the 4th logistics international conference (pp. 244-251).

Slack, R. J., Gronow, J. R., \& Voulvoulis, N. (2009). The management of household hazardous waste in the United Kingdom. Journal of Environmental Management, 90(1), 36-42.

Song, B. D., Morrison, J. R., Ko, Y. D., Van Santen, A., \& Voulvoulis, N. (2013). Efficient location and allocation strategies for undesirable facilities considering their fundamental properties. Computers \& Industrial Engineering, 65(3), 475-484.

Song, Q., \& Li, J. (2014). A review on human health consequences of metals exposure to, e-waste in China. Environmental Pollution, 196, 450-461.

Song, X. L., Wang, J. W., Yang, J. X., \& Lu, B. (2017). An updated review and conceptual model for optimizing WEEE management in China from a life cycle perspective. Frontiers of Environmental Science \& Engineering, 11(5), 1-12.

Srivastava, S. K. (2007). Green supply chain management: A state-of-the-art literature review. International Journal of Management Reviews, 9(1), 53-80.

Stowers, C. L., \& Palekar, U. S. (1993). Location models with routing considerations for a single obnoxious facility. Transportation Science, 27(4), 350-362.

Sun, X., Liu, X., Li, F., et al. (2017). Comprehensive evaluation of different scale cities' sustainable development for economy, society, and ecological infrastructure in China. Journal of Cleaner Production, 163, S329-S337. https://doi.org/10.1016/j.jclepro.2015.09.002

Tanskanen, P. (2013). Management and recycling of electronic waste. Acta Materialia, 61(3), 1001-1011.

Tao, J. G. (2008). Decision support system for E-waste reverse logistics based on the internet. In International conference of production and operation management (pp. 1328-1331).

Taslimi, M., Batta, R., \& Kwon, C. (2020). Medical waste collection considering transportation and storage risk. Computers \& Operations Research, 120, 104966.

Tesfaye, F., Lindberg, D. K., Hamuyuni, J., Taskinen, P., \& Hupa, L. (2017). Improving urban mining practices for optimal recovery of resources from e-waste. Minerals Engineering, 111(C), 209-221.

Triantafyllou, M. K., \& Cherrett, T. J. (2010). The logistics of managing hazardous waste: A case study analysis in the UK retail sector. International Journal of Logistics: Research and Applications, 13(5), 373-394.

Tsakona, M., Anagnostopoulou, E., \& Gidarakos, E. (2007). Hospital waste management and toxicity evaluation: A case study. Waste Management, 27(7), 912-920.

Tuzkaya, G., Onüt, S., Tuzkaya, U. R., \& Gulsun, B. (2008). An analytic network process approach for locating undesirable facilities: An example from Istanbul, Turkey. Journal of Environmental Management, 88(4), 970-983.

Ulukan, H. Z., \& Kop, Y. (2009). A two-step solution procedure to a fuzzy medical waste disposal facility location problem. In Joint international-fuzzy-systems-association world congress (pp. 1450-1455).

US Environmental Protection Agency (2009). Retrieved 7 May 2021, from https://www.epa.gov/hw/ learn-basics-hazardous-waste\#hwid. 
Vadoudi, K., Kim, J., Laratte, B., Lee, S. J., \& Troussier, N. (2015). E-waste management and resources recovery in France. Waste Management \& Research the Journal of the International Solid Wastes \& Public Cleansing Association ISWA, 33(10), 919-929.

Van Engeland, J., Beliën, J., De Boeck, L., \& De Jaeger, S. (2020). Literature review: Strategic network optimization models in waste reverse supply chains. Omega, 91, 102012.

Voudrias, E., \& Graikos, A. (2014). Infectious medical waste management system at the regional level. Journal of Hazardous, Toxic, and Radioactive Waste, 18(4), 04014020.

Wagner, T. P., Toews, P., \& Bouvier, R. (2013). Increasing diversion of household hazardous wastes and materials through mandatory retail take-back. Journal of Environmental Management, 123, 88-97.

Walery, M. (2014). Medical waste management planning system in the context of the model studies duration. Rocznik Ochrona Srodowiska, 16, 260-278.

Walery, M. J. (2017). Impact of capital and current costs changes of the incineration process of the medical waste on system management cost. IOP Conference Series: Earth and Environmental Science, 95(4), 042014.

Wang, F., Lai, X., \& Shi, N. (2011). Multi-Objective optimization for green supply chain network design. Decision Support Systems, 51(2), 262-269.

Wei, S., \& Zhang, K. (2008). Optimization model of e-waste reverse logistics and recycling network. In International conference on intelligent system and knowledge engineering, 2008, 1436-1442. IEEE.

White, C. D., Masanet, E., Rosen, C. M., \& Beckman, S. L. (2003). Product recovery with some byte: An overview of management challenges and environmental consequences in reverse manufacturing for the computer industry. Journal of Cleaner Production, 11(4), 445-458.

Wilson, C. A., Matthews, K., Pulsipher, A., \& Wang, W. H. (2016). Using geographic information systems to determine site suitability for a low-level radioactive waste storage facility. Health Physics, 110 (2 Suppl 1), S17.

Woodruff, T. J., \& Sutton, P. (2014). The Navigation Guide systematic review methodology: A rigorous and transparent method for translating environmental health science into better health outcomes. Environmental Health Perspectives, 122(10), 1007-1014.

Wu, H. L., Tao, F. M., \& Yang, B. (2020). Optimization of vehicle routing for waste collection and transportation. International Journal of Environmental Research and Public Health, 17, 4963.

Wyman, M. M., \& Kuby, M. (1995). Proactive optimization of toxic waste transportation, location, and technology. Location Science, 3(3), 167-185.

Xia, K., Gao, L., Wang, L. H., Li, W. D., Li, X. Y., \& Ijomah, W. (2016). Service-oriented disassembly sequence planning for electrical and electronic equipment waste. Electronic Commerce Research \& Applications, 20, 59-68.

Yao, L., Xu, Z., \& Zeng, Z. (2020). A soft-path solution to risk reduction by modeling medical waste disposal center location-allocation optimization. Risk Analysis, 40(9), 1863-1886. https://doi.org/10. 1111/risa.13509.

Yeh, C.-H., \& Xu, Y. (2013). Sustainable planning of e-waste recycling activities using fuzzy multicriteria decision making. Journal of Cleaner Production, 2013, 194-204.

Yesilnacar, M. I., \& Cetin, H. (2005). Site selection for hazardous wastes: A case study from the GAP area, Turkey. Engineering Geology, 81(4), 371-388.

Yilmaz, O., Kara, B. Y., \& Yetis, U. (2017). Hazardous waste management system design under population and environmental impact considerations. Journal of Environmental Management, 203, 720-731.

Yin, J. (2008). A fuzzy optimization modeling and algorithm on hazardous waste reverse logistics. In International conference on wireless communications, networking, and mobile computing (Vol. 2008, pp. 1-4). IEEE.

Yong, Z., Xu, L., Hai, M., \& Cheng, M. (2007). Designing a hazardous-waste reverse logistics network for third party logistics supplier under the fuzzy environment. In IEEE international conference on Service operations and logistics, and informatics, 2007. SOLI 2007 (pp. 1-6). IEEE.

Yoon, N. H., \& Jang, Y. C. (2006). The practice and challenges of electronic waste recycling in Korea with emphasis on extended producer responsibility (EPR). In IEEE international symposium on electronics and the environment (Vol. 2006, pp. 326-330). IEEE.

Yu, H., \& Solvang, W. D. (2016). Improved multi-objective programming with augmented $\varepsilon$-constraint method for hazardous waste location-routing problems. International Journal of Environmental Research and Public Health, 13(6), 548.

Yu, H., Sun, X., \& Solvang, W. D. (2020). A stochastic network design problem for hazardous waste management. Journal of Cleaner Production, 277, 123566. 
Yuksel, H. (2009). An analytical hierarchy process decision model for e-waste collection center location selection. In International conference on computers \& industrial engineering (Vol. 2009, pp. 16841689). IEEE.

Zeng, X. L., Song, Q. B., Li, J. H., Yuan, W. Y., Duan, H. B., \& Liu, L. L. (2015). Solving e-waste problem using an integrated mobile recycling plant. Journal of Cleaner Production, 90, 55-59.

Zhang, H. Y., Zhang, J., Liu, X. C., Yan, G. H., \& Liu, Y. Z. (2012). Research on the method of health assessment about the destruction equipment for high-risk hazardous chemical waste. Procedia Environmental Sciences, 16, 192-201.

Zhang, Y., \& Zhao, J. (2011). Modeling and solution of the hazardous waste location-routing problem under uncertain conditions. In ICTE (pp. 2922-2927).

Zhao, J., \& Huang, L. X. (2019). Multi-period network design problem in regional hazardous waste management systems. International Journal of Environmental Research and Public Health, 16, 11.

Zhao, J., Huang, L. X., \& Lee, D. H. (2016). Improved approaches to the network design problem in regional hazardous waste management systems. Transportation Research Part e: Logistics and Transportation Review, 88, 52-75.

Zhao, J., \& Ke, G. Y. (2017). Incorporating inventory risks in location-routing models for explosive waste management. International Journal of Production Economics, 193, 123-136.

Zhao, J., \& Verter, V. (2015). A bi-objective model for the used oil location-routing problem. Computers \& Operations Research, 62, 157-168.

Zhao, J., \& Zhao, J. (2010). Model and algorithm for hazardous waste location-routing problem. In ICLEM 2010: Logistics for sustained economic development: Infrastructure, information, integration (p. 2843-2849).

Zhao, J., \& Zhu, F. (2016). A multi-depot vehicle-routing model for explosive waste recycling. International Journal of Production Research, 54(2), 550-563.

Zoeteman, B. C. J., Krikke, H. R., \& Venselaar, J. (2010). Handling WEEE waste flows: On the effectiveness of producer responsibility in a globalizing world. International Journal of Advanced Manufacturing Technology, 47(5-8), 415-436.

Zografros, K. G., \& Samara, S. (1990). Combined location-routing model for hazardous waste transportation and disposal. Transportation Research Record, 1245, 52-59.

Publisher's Note Springer Nature remains neutral with regard to jurisdictional claims in published maps and institutional affiliations.

\title{
Authors and Affiliations
}

\section{Chunlin Xin ${ }^{1} \cdot$ Jie Wang ${ }^{1} \cdot$ Ziping Wang ${ }^{2} \cdot$ Chia-Huei Wu ${ }^{3} \cdot$ Muhammad Nawaz ${ }^{1}$. Sang-Bing Tsai $^{4}$ D}

\author{
Chunlin Xin \\ xinchl@mail.buct.edu.cn \\ Jie Wang \\ wangjie_0719@sina.com \\ Ziping Wang \\ ziping.wang@morgan.edu
}

Muhammad Nawaz

Nawazkhan7007@gmail.com

1 School of Economics and Management, Beijing University of Chemical Technology, 15 North 3rd Ring Rd. E., Chaoyang, Beijing 100029, People's Republic of China

2 Earl G. Graves School of Business and Management, Morgan State University, 1700 East Cold Spring Lane, Baltimore, MD 21251, USA

3 Department of Hotel Management and Culinary Creativity, Minghsin University of Science and Technology, Hsinchu, Taiwan 304, China 
4 Regional Green Economy Development Research Center, School of Business, WUYI University, Wuyishan 354300, People's Republic of China 